This item was submitted to Loughborough's Research Repository by the author.

Items in Figshare are protected by copyright, with all rights reserved, unless otherwise indicated.

\title{
Towards robust investment decisions and policies in integrated energy systems planning: Evaluating trade-offs and risk hedging strategies for remote communities
}

\section{PLEASE CITE THE PUBLISHED VERSION}

https://doi.org/10.1016/j.enconman.2020.113748

\section{PUBLISHER}

Elsevier

\section{VERSION}

AM (Accepted Manuscript)

\section{PUBLISHER STATEMENT}

This paper was accepted for publication in the journal Energy Conversion and Management and the definitive published version is available at https://doi.org/10.1016/j.enconman.2020.113748

\section{LICENCE}

CC BY-NC-ND 4.0

\section{REPOSITORY RECORD}

Quitoras, MR, P Cabrera, PE Campana, Paul Rowley, and C Crawford. 2020. "Towards Robust Investment Decisions and Policies in Integrated Energy Systems Planning: Evaluating Trade-offs and Risk Hedging Strategies for Remote Communities". Loughborough University. https://hdl.handle.net/2134/13514296.v1. 


\title{
Towards robust investment decisions and policies in integrated energy systems planning: Evaluating trade-offs and risk hedging strategies for remote communities
}

\author{
Marvin Rhey Quitoras ${ }^{\mathrm{a}, *}$, Pedro Cabrera ${ }^{\mathrm{b}}$, Pietro Elia Campana $^{\mathrm{c}}$, Paul Rowley ${ }^{\mathrm{d}}$, Curran \\ Crawford $^{\mathrm{a}}$ \\ ${ }^{a}$ Institute for Integrated Energy Systems at University of Victoria (IESVic), Department of Mechanical \\ Engineering, University of Victoria, PO Box 3055 STN CSC, Victoria, BC V8W 2Y2, Canada \\ ${ }^{b}$ Department of Mechanical Engineering, University of Las Palmas de Gran Canaria, Campus de Tafira s/n, \\ 35017 Las Palmas de Gran Canaria, Canary Islands, Spain \\ ${ }^{c}$ School of Business, Society \& Engineering, Mälardalen University, Box 883, SE-72123 Västerås, Sweden \\ ${ }^{d}$ Center for Renewable Energy Systems Technology (CREST), School of Electronic, Electrical ES Systems \\ Engineering, Loughborough University, Leics. LE11 3TU, UK
}

\begin{abstract}
Policy and investment decisions in developing clean energy strategies for remote communities are subject to multiple uncertainties that impact overall strategy outcomes, including those related to environmental emissions and energy costs. In this context, robust modelling approaches are required that can clarify potential outcomes while subject to such uncertainties. This work introduces a novel modeling framework that enables enhanced decision making in energy systems planning for remote communities, which for the first time takes into account context-specific decision-maker attitudes towards multiple inter-related uncertainties and various energy solution philosophies. In particular, multiple energy system configurations are evaluated by simultaneously minimizing the levelised cost of energy and fuel consumption, with a test case for a specific community in the Northwest Territories, Canada. The concept of model robustness and validity together with the stochastic nature of uncertain parameters are combined in a multi-objective optimization framework that elucidates the full spectrum of energy solutions available in such a remote Arctic context. Introducing known uncertainties in renewable energy characteristics was found to reduce overall energy yields from the renewable energy technologies. Specifically, the deterministic renewable energy penetration of $69 \%$ from a specific energy system configuration reduced to a mean of $51 \%$ after the inclusion of uncertainties via probabilistic simulation. Conversely, diesel fuel consumption increased to 750,000 L/yr (mean) from its initial deterministic value of 447,470 L/yr. Holistic energy solutions which include both supply and demand-side considerations are also analysed. Specifically, a reduced community domestic heating load of $40 \%$ was achieved via retrofit of high performance building fabric enclosures evaluated in conjunction with renewable energy supply options. Ultimately, insights and real-world applications have been synthesized to provide coherent recommendations on strategies to address energy security, energy affordability and environmental sustainability, along with meaningful propositions towards Indigenous community-led energy projects in a range of contexts.
\end{abstract}

\section{Highlights}

- A robust modeling approach to handle uncertainties in energy planning is presented.

- The decision-maker risk preference towards uncertainty is considered in the model.

- Informed energy policy facilitates Indigenous community-led energy projects.

Keywords: Energy policy; Robust optimization; Uncertainty; Risk hedging

strategies; Indigenous peoples; Energy sovereignty

\footnotetext{
${ }^{*}$ Corresponding author

Email address: mdquitoras@uvic.ca (Marvin Rhey Quitoras)
} 


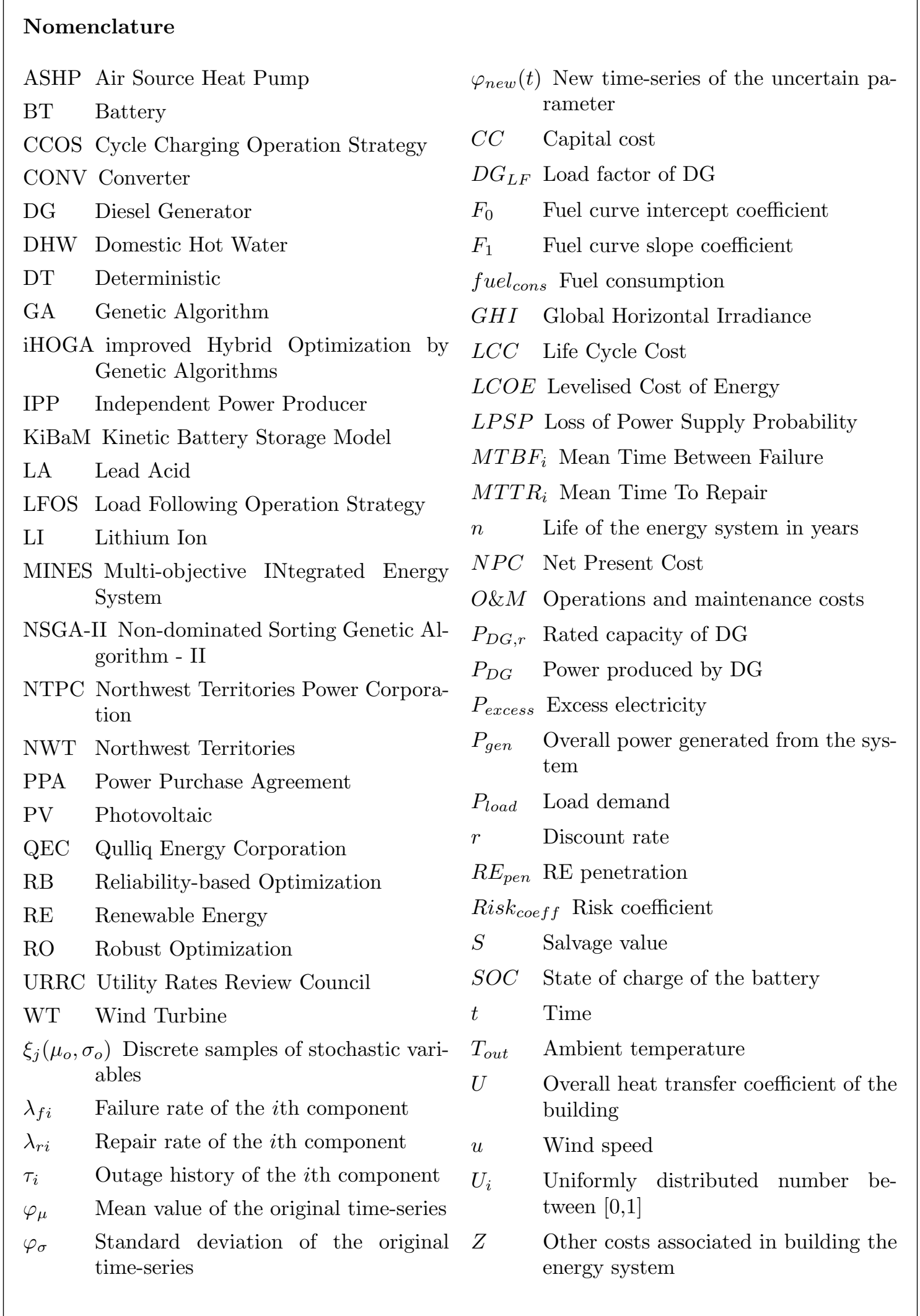

\section{1. Introduction}

Understanding the dynamic complexities of energy systems, the long term consequences of 3 investment decisions, and the critical role of implementing robust policy frameworks requires in4 novative approaches in dealing with energy systems planning uncertainties. Krey and Riahi [1] 


\footnotetext{
${ }^{1}$ The North in Canada politically refers to the territories of Yukon, NWT and Nunavut; the use of the term

Canada's Arctic for this work is inclusive of the three territories mentioned.
}

expounded that ignorance with respect to the multitude of uncertainties can be very costly, and highlighted the significance of improved capturing of the trade-offs and risks resulting from multiple systemic uncertainties. However, despite these risks, the challenges of understanding, assessing and communicating impacts of uncertainties for energy system policy makers remain significant and are poorly evaluated in previous research [2.

This study demonstrates the application of a flexible probabilistic approach based upon robustly assessing multiple uncertainties in a holistic energy modeling framework. The case study of a remote Northern community illustrates the resulting impacts on energy policy and investment strategies from a multi-domain perspective. Holistic energy considerations and trade-offs in transitioning Arctic and more generally remote communities globally from fossil-fuel dependency is also taken into consideration, while balancing the trilemma of challenges [3] relating to energy security, energy affordability and environmental sustainability.

\subsection{Literature review}

The literature survey conducted for this work presents an overview of existing energy policies and initiatives in reducing diesel dependence in Northern Canada. Further, this section describes techniques in modeling uncertainties in energy systems optimization as it is critical in designing strong policies and will inform decision making across various levels in achieving energy transitions.

\subsubsection{Overview of energy policies in the Canadian North}

To identify existing energy policies that accelerate and support energy transitions, a crossCanada scan of diesel reduction initiatives and clean energy policies has been conducted by the Pembina Institute 4. The study particularly focused on policies, programs and regulations that impact energy systems in remote Indigenous communities at the federal, provincial, regulatory and utility levels. The three territories in the North ${ }^{1}$ have various strategies to increase energy security and ensure affordable cost of energy, while transitioning to a lower-carbon economy. For example, the existing initiatives and policies designed for reducing diesel dependence in the Northwest Territories (NWT) include [5]:

- Alternative Energy Technologies Program - provides funding for communities and commercial businesses in developing $\mathrm{RE}$ projects such as solar, wind, wood pellet heating, and biofuel/synthetic gas, among others;

- Community Government Building Energy Retrofit Program - supports upgrades to community government-owned buildings in order to reduce electrical and heat loads;

- Commercial Energy Conservation and Efficiency Program - encourages commercial businesses to conserve energy and improve their energy efficiency in the form of rebates;

- Energy Efficiency Incentive Program - designed to provide rebates for residents and nonprofit organizations after purchasing energy efficient appliances, heating appliances, LED light bulbs, and drain water heat recovery systems;

- Net Metering - allows customers of the Northwest Territories Power Corporation NTPC) to generate their own power and then send any surplus in the electricity grid of their community.

It should be highlighted that there is no documented Independent Power Producer (IPP) policy in the NWT, and IPP project proposals are subject to government and utility negotiations (to be further discussed in Section 3.4). A community-oriented IPP policy that offers competitive Power Purchase Agreements (PPA $)$ would potentially facilitate Indigenous community-led energy projects. For this reason, the Pembina Institute argued that the NWT is a critical jurisdiction in Canada given the number of Indigenous remote communities (Table 1) in the Territory [4. 
Table 1: Number of PPAs among Indigenous remote communities in Canada 6].

\begin{tabular}{llll}
\hline Jurisdictions & $\begin{array}{l}\text { Number of } \\
\text { communities }^{\mathrm{a}}\end{array}$ & $\begin{array}{l}\text { No. of PPA } \\
\text { net metering) }\end{array}$ & $\begin{array}{l}\text { Project } \\
\text { types }\end{array}$ \\
\hline British & 25 & $\begin{array}{l}4 \text { current } \\
3 \text { developing }\end{array}$ & $\begin{array}{l}\text { Micro-hydro } \\
\text { Solar }\end{array}$ \\
Columbia & & 0 current & Biomass \\
Alberta & 7 & 0 current & N/A \\
Saskatchewan & 1 & 0 current & N/A \\
Manitoba & 4 & $\begin{array}{l}7+\text { current } \\
2 \text { developing }\end{array}$ & Solar \\
Ontario & 25 & 0 current & N/A \\
Quebec & 19 & 0 current & N/A \\
Newfoundland & 16 & 0 current & Wind \\
Yukon & 21 & 1 developing & Solar \\
NWT & 26 & 1 current & N/A \\
\hline Nunavut & 25 & 0 current & Nat \\
\hline
\end{tabular}

${ }^{\mathrm{a}}$ Indigenous remote communities - comprised of First Nations, Metis or Inuit peoples of Canada.

\subsubsection{Modeling uncertainties and scenarios in other countries}

Policy frameworks to meet decarbonization targets and energy security goals must contend with multiple and overlapping uncertainties [2]. Usher and Strachan [7] emphasized that previous studies on energy systems modeling have failed to address the significant uncertainties surrounding many aspects of the transition to a low-carbon future in an integrated and systematic manner. They argued that this is the result of: (i) challenges involved in applying solely a deterministic approach to a complex and multi-faceted problem that is inherently uncertain, and (ii) the issues associated with so much effort being input by the energy modeling community on pathways and technologies rather than uncertainties. Pfenninger et al. 8, provided a comprehensive study of current challenges on energy systems modeling and efforts being taken to address them. One of the concerns they highlighted was in addressing the growing complexity of energy systems in terms of optimization approaches across various scales (spatial resolution), as shown in Fig. 1 . From a modeling perspective, scale pertains to the boundary of a modeled system, so large-scale energy models cover an entire continental region with coarse temporal resolution, while small-scale energy models look at a residential or community level with a high temporal resolution. The inherent trade-offs in resolutions and simplifying assumptions influence the level of uncertainties in model outputs due to the associated computational demands in solving energy system optimization problems.

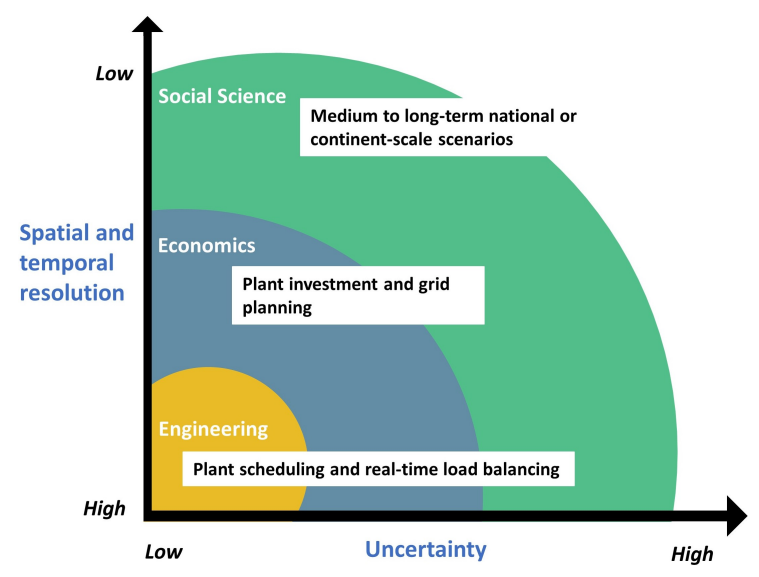

Figure 1: Optimization complexity across various spatial and temporal scales; adapted from 8 .

In the majority of previous studies involving energy systems modeling, uncertainties are typ68 ically treated by performing sensitivity analyses for a given range of input parameters. This 
approach provides understanding of the uncertainty space and to a certain extent, the future risks involved in understanding the complexities of an integrated energy system. However, this approach should be complemented with further analysis exploring the impact of uncertainties in a non-deterministic fashion. For example, Mavromatidis et al. 9] conducted research on designing a distributed energy system for a Swiss neighborhood by performing two-stage stochastic programming that included multiple objective functions to capture decision-maker preferences on risks resulting from uncertainties. Hamarat et al. [10 focused on multi-objective robust optimization in specifying appropriate conditions for adapting energy policies by exploring transition pathways that lead to satisfactory results across a large ensemble of scenarios in the European Union. Similarly, Majewski et al. 11 carried out a minmax robust multi-objective optimization, through a mixed-integer linear programming formulation, to identify the trade-off between economic and ecological criteria in designing sustainable energy systems.

Reliability-based optimization (RB), meanwhile, is another optimization technique suitable for use in the presence of uncertainty. This method aims at finding the best solution that satisfies the constraints with a specified probability distribution [12. Clark and DuPont 13] applied this approach in decreasing operations and maintenance costs in designing offshore renewable energy systems. Chu et al. 14 expanded the RB optimization process by creating surrogate models with metaheuristic methods such as genetic algorithm and simulated annealing. Despite the evident advantages of RB optimization, its real-world application is quite challenging due to high numerical costs involved in its solution of the reliability constraints 15 .

In previous Arctic energy system studies, Ringkjob et al. [16 presented a stochastic longterm (2015 - 2050) energy model for a remote Arctic settlement in Longyearbyen, Svalbard. The TIMES modeling framework was employed. This model followed a linear programming approach to minimise the total system cost. The inherent trade-off of this long-term energy system analysis is its inability to track in detail the performance of each energy system component over the whole modeling horizon because of the computational expense of the energy model.

\subsection{Research questions and key contributions}

The literature survey indicates that various techniques for assessing uncertainties in energy systems modeling are available. However, executing such approaches and implementing them in the evaluation of a range of holistic energy solutions, especially in the Arctic region, are generally scarce. In general, previous work has taken a high-level focus on renewable energy (RE) pathways rather than looking at: (i) a wide array of energy solution initiatives (both supply and demand aspects), (ii) the technical details on the variability of the $\mathrm{RE}$ resources, and (iii) the types of energy storage available for both electricity and heating. Further, previous analyses on uncertainty modeling were found to be limited in terms of generating insights and recommendations from the energy model outputs, and designing adaptive and robust energy policies to accelerate energy transitions. Hence, this work builds upon the previous work of the authors in [17] wherein holistic energy solutions were introduced for the Canadian Arctic, balancing decision makers' diverse and multiple solution philosophies in addressing the energy trilemma.

With this framing in mind, the overarching research questions for this work are based on the current energy situation in the North as reflected in previous Energy Charette $2^{2}$, and the research gaps pointed out earlier. These research questions can be summarized as:

1. How to effectively integrate uncertainties in energy systems modeling in the Arctic given energy resource variability and future climate change impacts in the region?

2. How do extreme temperature events impact battery $(\overline{B T})$ storage operation in the Arctic region?

3. How to advance diesel reduction initiatives in Northern latitude communities while considering risks from multiple uncertainties?

4. How can private, government and non-government entities support Indigenous-led energy projects?

\footnotetext{
${ }^{2}$ Energy Charette is a collaborative planning process where Northern communities, government and nongovernment organizations, industry, elders, Indigenous peoples, and energy experts come together to develop an energy strategy and plan for the future.
} 
The main aim of this work is to bridge the gaps in previous research by establishing methods to address uncertainties in energy systems modeling, while taking into account coordinated climate and energy policies from the private sectors, Indigenous communities, governments, utilities, regulators, and other stakeholders. In particular, the four key research questions as mentioned previously are addressed by the novel contributions of this work:

1. Development of a robust Multi-objective INtegrated Energy System (MINES) model that captures decision-maker attitudes towards multiple overlapping uncertainties in designing integrated energy systems;

2. Assessment of lead acid and lithium-ion BT storage systems while taking into account impacts of BT capacity decrease from freezing temperatures in cold climate settings;

3. Adaptation of holistic energy solutions in transitioning towards robust and sustainable energy systems while addressing trade-offs and uncertainties in reducing diesel dependence;

4. Formulation of insights and recommendations on how to address barriers and opportunities in implementing strong energy policies and risk hedging strategies in remote communities.

The rest of the article is organized as follows: Section 2 describes the model developed for the study. To demonstrate functionality of the energy model developed in this work, Section 2.6 presents relevant information for the case-study community, namely Sachs Harbour in the NWT the information presented will serve as input data for the model. Section 3 summarizes the results of the test case for the method. Section 3.4 presents insights and recommendations for policy makers and various practitioners according to the quantitative outputs generated from the model. Finally, Sections 4 and 5 discuss the conclusions and future work from this study.

\section{Methods}

The schematic diagram of a prototypical integrated energy system studied in this work is shown in Fig. 2. It consists of wind turbine, solar PV, battery storage, diesel generator and a bidirectional converter to faciliate power flows from the DC bus to AC bus and vice versa. Thermal (space heating and domestic hot water) and electrical loads were modeled for each $1 \mathrm{~h}$ timestep over a given year.

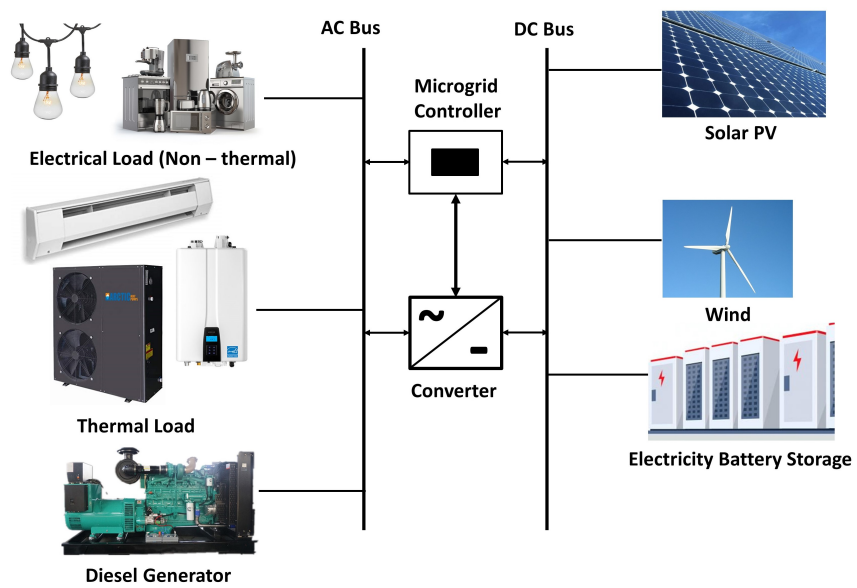

Figure 2: Schematic diagram of a prototypical integrated electrical and thermal energy system.

\subsection{Robust optimization}

The MINES model implements a multi-objective optimization approach to capture complex trade-offs in designing integrated energy systems. This technique provides a diversity of solutions which are critical in capturing various solution philosophies in transitioning remote communities in the Arctic towards sustainable sources of energy. In particular, the Non-dominated Sorting Genetic Algorithm - II (NSGA-II) of Deb et al. [18] was adopted for this study. It selects individuals by nondomination rank ${ }^{3}$ taking as many complete ranks as will fit in the new population. This process

\footnotetext{
${ }^{3}$ The non-domination rank is obtained by finding the near-optimal Pareto front for the whole population; these points are given a rank of 1 and then removed from the population. The near-optimal Pareto front for the remaining
} 


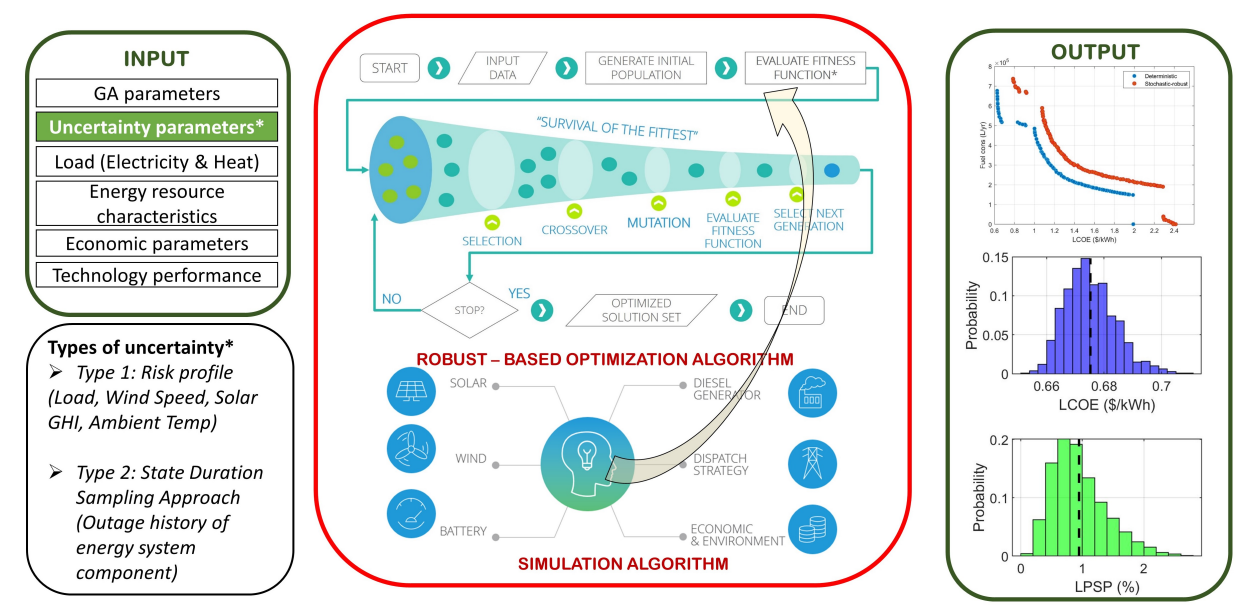

Figure 3: Overall energy modeling framework of MINES.

Table 2: GA configuration parameters.

\begin{tabular}{ll}
\hline Parameter & Description \\
\hline Algorithm & Variant of $[$ NSGA-II $[18]$ \\
Generations & 200 \\
Population & 100 \\
Crossover function & Heuristic \\
Crossover rate(\%) & 90 \\
Mutation function & Non-uniform \\
Tournament size & 2 \\
\hline
\end{tabular}

drives the population towards the near-optimal Pareto front 20] while maintaining diversity along the front [19]. Further, NSGA-II was selected as it has the generic ability to handle multi-objective trade-offs and near-optimal Pareto front pursuit, as proven in previous studies by Evins et al. 19. and Forde et al. 21]. The set of Genetic Algorithm (GA) input parameters for this work is listed in Table 2 and the approach was implemented in a MATLAB ${ }^{\circledR}$ platform.

For this work, the robust-based aspect was integrated into the optimization algorithm of the MINES model. There are many notions of robustness, including a good expected performance, a good worst-case performance, a low variability in performance, or a large range of disturbances still leading to acceptable performance [12]. Beyer and Sendhoff [22] conducted a comprehensive survey on robust optimization $(\mathrm{RO})$, and described four types of uncertainties as related to realworld system designs; interested readers are referred to their work.

According to Gazijahani and Salehi 23, the undefined nature and poor availability of data about uncertain modeling parameters determine the most suitable approach in addressing uncertainties in a decision making framework. They argued that $\mathrm{RO}$ is the most suitable optimization technique in controlling the worst possible scenarios in designing microgrids due to the nature and the lack of full information of the uncertainties involved in the energy system. In this paper, a minmax principle was adapted to seek the optimal value of each decision variable under the worstcase realization of uncertainties. The mathematical representation of this concept is presented in Eq. 11 24:

$$
\min \left[\sup _{\Xi} f_{1}(z, \xi), \sup _{\Xi} f_{2}(z, \xi), \ldots, \sup _{\Xi} f_{M}(z, \xi)\right]
$$

where $f_{M}(z, \xi)$ are the objective functions, $z \in Z$ represents a vector of decision variables, $\xi \in \Xi$ pertains to a vector of random variables, and $\sup (:)$ indicates the worst-case scenario of the specific objective function. The worst-case realizations of uncertainties (robust-based optimization) was

points is found; these points are given a rank of 2 and then removed from the population, and so on until all points are ranked [19]. 
Table 3: The 11 discrete variables in the optimization algorithm.

\begin{tabular}{|c|c|}
\hline Parameter & Value \\
\hline WT quantity & $0-500$ \\
\hline WT capacity (kW) & $95,95,100,100$ \\
\hline PV quantity & $0-500$ \\
\hline$\overline{\mathrm{PV}}$ capacity $(\mathrm{kW})$ & $15,25,20,25.025$ \\
\hline BT quantity & $0-500$ \\
\hline$\overline{\mathrm{BT}}$ capacity (kWh) & $55,13.9,7.37,9.24$ \\
\hline $\overrightarrow{\mathrm{DG}}$ quantity & $0-100$ \\
\hline DG capacity $(\mathrm{kW})$ & $300,320,225,150$ \\
\hline CONV quantity & $0-10$ \\
\hline CONV capacity $(\mathrm{kW})$ & $200,250,270,300$ \\
\hline Operation strategy & LFOS and CCOS \\
\hline
\end{tabular}

adopted as it captures the unique considerations of decision makers in Arctic communities.

Aside from energy systems applications, RO has the generic ability to handle a wide variety of optimization problems and has been used extensively on other fields such as internet routing 25], business aircraft [26], machine scheduling [27], and intensity-modulated proton therapy [28], among others. $\mathrm{RO}$ has also been implemented in combination with various types of evolutionary algorithms as executed in previous studies done by Goh and Tan [29, Kuroiwa and Lee [30, and Wang et al. 31. The algorithm behind the MINES modeling framework, NSGA-II has also been applied in conjunction with RO as introduced by Deb and Gupta 32.

The justifications given for the $\mathrm{RO}$ approach and combining it with the multi-objective approach of the MINES model provides decision makers with the ability to balance and analyze trade-offs between investment decisions and environmental impacts of the energy system, while considering multiple overlapping uncertainties.

\subsection{Quantifying complex trade-offs in the energy system design space}

The multi-objective technique of MINES unlocks the full spectrum of energy solutions available in the Arctic. With this approach, a trade-off analysis can be done by analyzing two objective functions simultaneously. In this study, Levelised Cost of Energy LCOE (Eq. 2) 33 was formulated as the first objective function to represent energy affordability as a major concern based on the previous Energy Charettes in the NWT 34]:

$$
L C O E=\frac{\sum_{t=1}^{n} \frac{C C_{i}(t)+O \& M_{i}(t)+Z_{i}(t)-S_{i}}{(1+r)^{t}}}{\sum_{t=1}^{n} \frac{P_{g e n}}{(1+r)^{t}}}
$$

where $t$ is time (year), $r$ is the discount rate $(\%), n$ is the total life of the energy system (year), $C C$ is the capital cost $(\$)$ per unit of the system component $i, O \& M$ is the operations and maintenance costs (\$/year), $Z$ is all other costs associated with the project (\$/year), $S$ is the salvage value $(\$)$, and $P_{\text {gen }}$ is the power generated from the energy system (kWh/year).

The [DG]s fuel consumption (fuel $l_{\text {cons }}$, as shown in Eq. 3, was formulated as the second objective function in the model. This approach leads to a quantitative investigation of tradeoffs between alternative sources of energy in the Arctic while observing low cost of energy (first objective function) for the community.

$$
\text { fuel }_{\text {cons }}=F_{0} P_{D G, r}+F_{1} P_{D G}
$$

where $F_{0}$ is the fuel curve intercept coefficient $\left(\mathrm{L} / \mathrm{h} / \mathrm{kW}_{\text {rated }}\right), F_{1}$ is the fuel curve slope coefficient $(\mathrm{L} / \mathrm{h} / \mathrm{kW}), P_{D G, r}$ is the rated capacity of $\mathrm{DG}$ and $P_{D G}$ is the instantaneous power coming from the $\mathrm{DG}(\mathrm{kW})$.

Table 3 shows the 11 discrete decision variables implemented in the model. The two operation strategies modeled were the Load Following Operation Strategy (LFOS) and Cycle Charging Operation Strategy (CCOS 35. In both strategies, the DG only operates when there is a deficit of power and the renewables or the BT storage system cannot meet the load. With LFOS, the 
DG is dispatched to provide the exact power to meet the instantaneous load. CCOS dispatches the DG power always at its rated capacity to maximize generator efficiency; instantaneous surplus of power goes to the BT storage system. Also, the full set of constraints considered to run the optimization module in MINES are:

$$
\text { constraints }\left\{\begin{array}{l}
L P S P \leq 0 \% \\
S O C_{\text {min }} \geq 30 \% \\
R E_{\text {pen }} \geq 30 \% \\
P_{\text {excess }} \leq 30 \% \\
D G_{L F} \geq 30 \%
\end{array}\right.
$$

where $L P S P$ is the Loss of Power Supply Probability (\%), $S O C$ is the state of charge of the $\mathrm{BT}(\%)$, $R E_{\text {pen }} \mid$ is the RE penetration (\%), $P_{\text {excess }}$ is the excess electricity (\%), and $D G_{L F}$ is the load factor of the DG (\%). The mathematical formulation of each constraint and their respective justifications to include in the model were described previously by the authors in [35]. The component sub-models including the specific technology input parameters (solar $\mathrm{PV}, \mathrm{WT}, \mathrm{BT}, \mathrm{DG}, \mathrm{CONV}$ ) as laid out in Fig. 2 were described in detail by the authors in 35 .

\subsection{Uncertainty propagation}

Two types of uncertainties were introduced in MINES. The first type refers to the meteorological variables relevant for the community as well its load profile. The second type of uncertainty pertains to the operational reliability of each component in the integrated energy system. The two types of uncertainty ensure robustness of the energy system being proposed for remote communities in the Arctic.

\subsubsection{Integrating risk hedging strategies in robust optimization}

The first type specifically relates to uncertainties from the load profile of the community $\left(P_{\text {load }}\right)$ as well as various meteorological parameters including Global Horizontal Irradiance $(G H I)$, wind speed $(u)$ and the ambient temperature $\left(T_{\text {out }}\right)$. The approach is a modified version of the probability analysis being implemented through the improved Hybrid Optimization by Genetic Algorithms (iHOGA software 36. The iHOGA commercial software is a well-established tool in optimizing energy systems, both deterministically and probabilistically. Using iHOGA, Zubi et al. [37] conducted a techno-economic assessment of an off-grid $\mathrm{PV}$ system for developing regions to provide electricity for basic domestic needs. Dufo-Lopez et al. 38] conducted a similar study by optimizing a stand-alone hybrid solar-diesel-battery energy system for an off-grid health care facility while considering uncertainties from solar irradiance and the load demand. Other applications of the iHOGA software can be found in Fulzele and Daigavane 39, Fracastoro et al. 40, Bernal-Agustin et al. 41] and Cristobal-Monreal et al. 42, among others.

The probability analysis in iHOGA can be performed by taking into account the Gaussian probability distribution of the mean annual values of the system load, solar irradiance, wind speed and water flow (if there is a water turbine in the system). The software performs its simulation by assigning each uncertain parameter with five possible increments/reductions from the original time-series:

- Average

- Average + Standard Deviation

- Average - Standard Deviation

- Average $+3^{*}$ Standard Deviation

- Average - $3^{*}$ Standard Deviation

For example, the user can assign Average + Standard Deviation for load, and for the solar irradiance, wind and water flow data, the Average - Standard Deviation. This combination implies that there is an increment from the original time-series of the load data while there is a reduction in the other uncertain variables in reference to the original time-series [36. In conjunction with the second type of uncertain parameters (relating to system reliability), this paper improves the iHOGA probabilistic technique by explicitly introducing decision-maker risk preferences (captured 
Table 4: Risk coefficients as introduced in the robust-based optimization of the MINES model.

\begin{tabular}{llll}
\hline Uncertain Parameter & Risk seeking & Risk neutral & Risk averse \\
\hline Load & +1 & +2 & +3 \\
\hline$u$ & -1 & -2 & -3 \\
\hline$\overline{G H I}$ & -1 & -2 & -3 \\
\hline $\bar{T}_{\text {out }}$ & +1 & +2 & +3 \\
\hline
\end{tabular}

Table 5: Meteorological and load uncertainty parameters/assumptions for Sachs Harbour.

\begin{tabular}{llll}
\hline Parameter & Mean & Standard Deviation & $\begin{array}{l}\text { Number of } \\
\text { Years }^{\mathrm{a}}\end{array}$ \\
\hline Average $u$ for a year & $8.075 \mathrm{~m} / \mathrm{s}$ & $0.290 \mathrm{~m} / \mathrm{s}^{\mathrm{b}}$ & 10 \\
Average $\bar{T}_{\text {out }}$ for a year & $-10.31{ }^{\circ} \mathrm{C}$ & $2.4^{\circ} \mathrm{C}^{\mathrm{c}}$ & 55 \\
Average daily GHI for a year & $2.471 \mathrm{kWh} / \mathrm{m}^{2}$ & $0.618 \mathrm{kWh} / \mathrm{m}^{\mathrm{d}}$ & - \\
Average combined daily thermal & $9,277 \mathrm{kWh}$ & $927 \mathrm{kWh}$ & - \\
and electricity load for a year & & & \\
\hline
\end{tabular}

a Set of several years in reference to the standard deviation.

b Adapted from Tuktoyaktuk, NWT 43 .

c Adapted from average temperature (1957 - 2012) increase for four communities in the NWT 44.

d Considered $25 \%$ of interannual variation 45 .

e Considered $10 \%$ of interannual variation for $P_{\text {load }}$

by a risk coefficient) towards the first types of uncertain parameters mentioned previously, and as shown in Eq. 5 .

$$
\varphi_{\text {new }}(t)=\overbrace{\left(\frac{\varphi_{\text {old }}(t)}{\varphi_{\mu}}\right)}^{\text {data normalization }} \underbrace{\left(\varphi_{\mu} \pm R i s k_{\text {coeff }} \cdot \varphi_{\sigma}\right)}_{\text {discrete samples (increment/reduction) }}
$$

where $\varphi_{\text {new }}(t)$ is the new time-series of the uncertain parameter, obtained from its original mean value $\left(\varphi_{\mu}\right)$ and standard deviation $\left(\varphi_{\sigma}\right)$. The original time-series was divided by its mean to ensure that each time-series will be proportional to the original. It can be observed that when the Risk $k_{\text {coeff }}$ in Eq. 5 is zero, the algorithm reverts to a deterministic optimization (i.e old time-series is active). On the other hand, the probabilistic feature of MINES is active when the $\operatorname{Risk}_{\text {coeff }}$ is set to a non-zero value. Specifically, this work introduces various risk attitudes of the decision maker towards uncertainty in energy system planning as presented in Table 4 . The Risk coeff in the riskaverse column in Table 4 implies best performance of the energy system (i.e optimal value of the objective functions) against worst-case realizations of the uncertain parameters. Alternatively, the Risk $_{\text {coeff }}$ in the risk-seeking column appeals to a relatively more optimistic/risk-seeking decisionmaker. An intermediate risk attitudes in the middle column (neither risk seeking nor risk averse) corresponds to a a risk-neutral decision-maker for this study.

The increment/reduction in the second term of Eq. 5 also pertains to the discrete samples $\xi_{j}\left(\mu_{o}, \sigma_{o}\right)$ of the stochastic variables wherein $j$ is the number of samples (number of realization of uncertainties) and $o$ is the uncertain variable. Through Latin Hypercube Sampling, the algorithm draws a total of $j$ random samples from the probability distribution $\xi_{j}\left(\mu_{o}, \sigma_{o}\right)$ represented by its mean $\varphi_{\mu}$ and standard deviation $\varphi_{\sigma}$. Table 5 lists the respective means and standard deviations of the uncertain parameters described in this section.

\subsubsection{Uncertainty on system reliability}

To ensure robust operation of the energy system in the Arctic and avoid the possibility of having to fly-in emergency fuel to these remote communities (as what occured in Paulatuk, NWT during the summer of 2019 [6]), the $L P S P$ has been set to $0 \%$ as part of the model constraints (Eq. 4). The 0\% LPSP implies consistent and efficient operation of the entire energy system components. However, this ideal situation has to be investigated given the operational complexity 
of an integrated energy system. Hence, a sequential Monte Carlo state duration sampling has been incorporated in MINES to address uncertainty in reliability of the energy system components. This approach was adapted from the power system reliability simulation technique introduced by Billinton and $\mathrm{Li}$ [47, and uses component state duration distribution functions (refer to Appendix A.

Fig. 4 presents the overall uncertainty propagation process for the multiple overlapping uncertainties considered in this work. Specifically, the uncertainty formulation results in a set of input probability distribution functions that are mapped to various outputs (system reliability, economics and environmental) in the MINES model. This step involves solving the multi-objective optimization problem by repeating the uncertainty propagation process multiple times based on the number of realizations of uncertainties set by the modeler. Similar to the iHOGA software 42, the mean of each performance metric was taken into account in comparing all feasible configurations of the energy system, and this will be reflected in the non-dominated individuals (near-optimal Pareto front) of MINES.

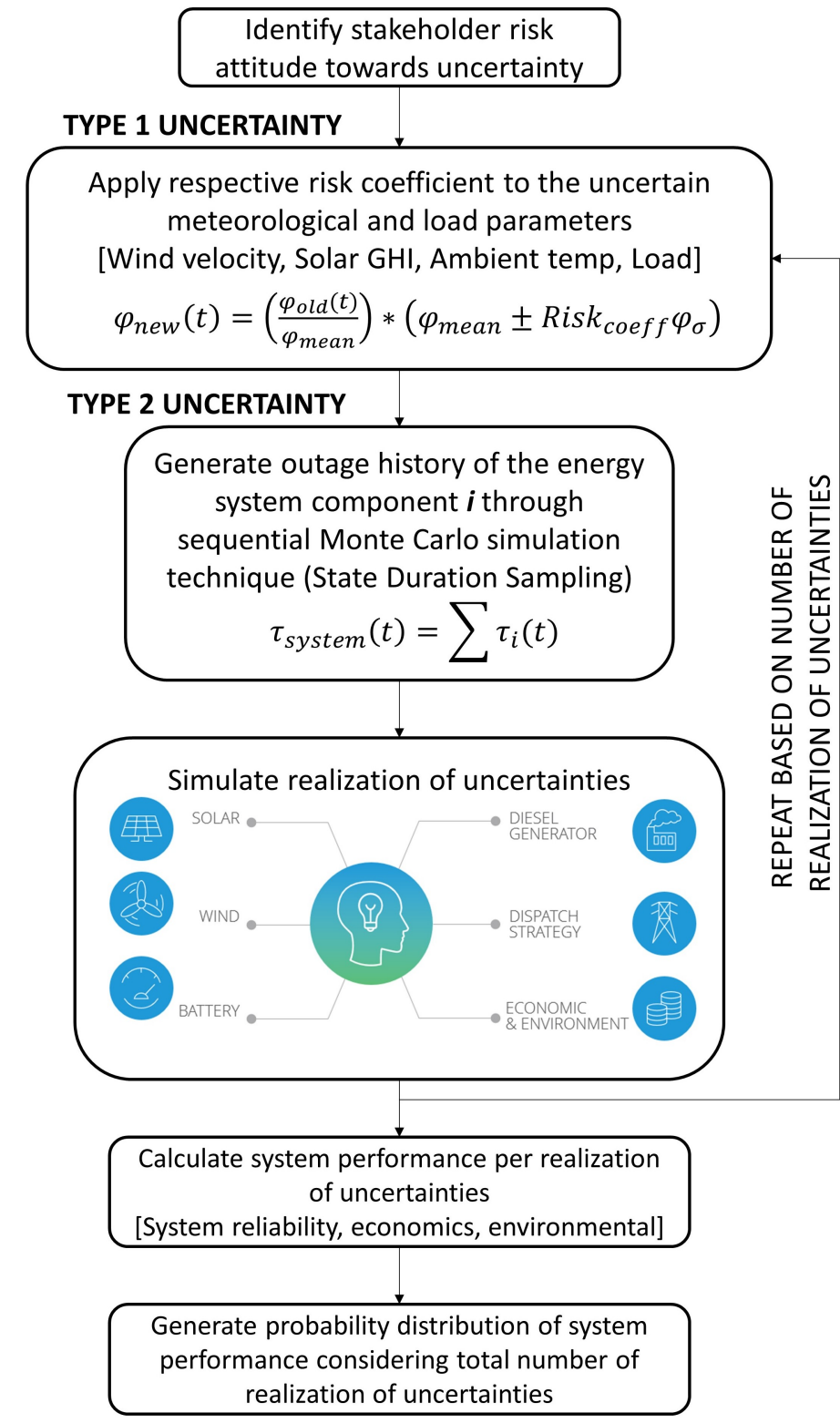

Figure 4: Uncertainty propagation of the proposed modeling framework.

\subsection{Temperature effect on battery storage systems}

The World Wildlife Fund conducted a set of feasibility studies 48 for the Canadian Arctic communities using the HOMER software [4]. HOMER is a tool originally developed by the 
Table 6: Battery storage thermal parameters.

\begin{tabular}{llll}
\hline Parameter & Unit & Lead Acid & Lithium Ion \\
\hline Model & - & T-105 with Bayonet Cap [51] & TR 25.6-25 Li-ion [52] \\
Manufacturer & - & Trojan Battery & Trojan Battery \\
Max operating temp. & ${ }^{\circ} \mathrm{C}$ & 55 & 45 \\
Min operating temp. & ${ }^{\circ} \mathrm{C}$ & -20 & -20 \\
Conductance to ambient & $\mathrm{W} / \mathrm{K}$ & 10 & 10 \\
Specific heat capacity & $\mathrm{J} / \mathrm{kg}-\mathrm{K}$ & 800 & 800 \\
Fixed bulk temp. & ${ }^{\circ} \mathrm{C}$ & 20 & 20 \\
\hline
\end{tabular}

National Renewable Energy Laboratory in the United States. It determines the most feasible configuration of the energy system by applying a full factorial design of experiments, and choosing the configuration with minimum Net Present Cost (NPC) [50]. In this paper, the HOMER modeling framework was used to evaluate lead acid (LA) and lithium ion (LI) battery storage in cold climate regions using the modified Kinetic Battery Storage Model (KiBaM $)$. In particular, the determined optimal capacity of the battery storage system from MINES will be further investigated by incorporating temperature effect on battery storage capacity.

The thermal parameters of the battery storage used for this work are listed in Table 6. The minimum and maximum operating temperature should be observed in simulating battery performance. Outside the given temperature range, the battery shuts off, and neither charging nor discharging is allowed. Fig. 5 shows the temperature versus capacity curve of the two types of battery considered in the simulation. In Table 6, conductance to ambient refers to the rate at which heat is exchanged between the battery components and the building where the battery is located. Specific heat capacity refers to the amount of heat energy the component absorbs, per kilogram of mass, before increasing in temperature by one degree Celsius. In order to demonstrate the impact of temperature on the overall energy system performance, the mentioned parameters will be considered in simulating the hourly dispatch of the battery after getting the deterministic optimal configuration of the energy system. In theory, this demonstrates the thermal variation of the battery at each time step in the model. However, only the fixed bulk temperature will be considered in the probabilistic optimization algorithm of MINES because: (i) in real-world applications, battery storage systems are typically installed in a building with thermal management, and (ii) this approach also reduces significantly the computational requirement of the optimization algorithm. In other words, this study assumed that the fixed bulk temperature of $20^{\circ} \mathrm{C}$ of the battery will be maintained through the temperature regulator installed in the building where the battery is located.

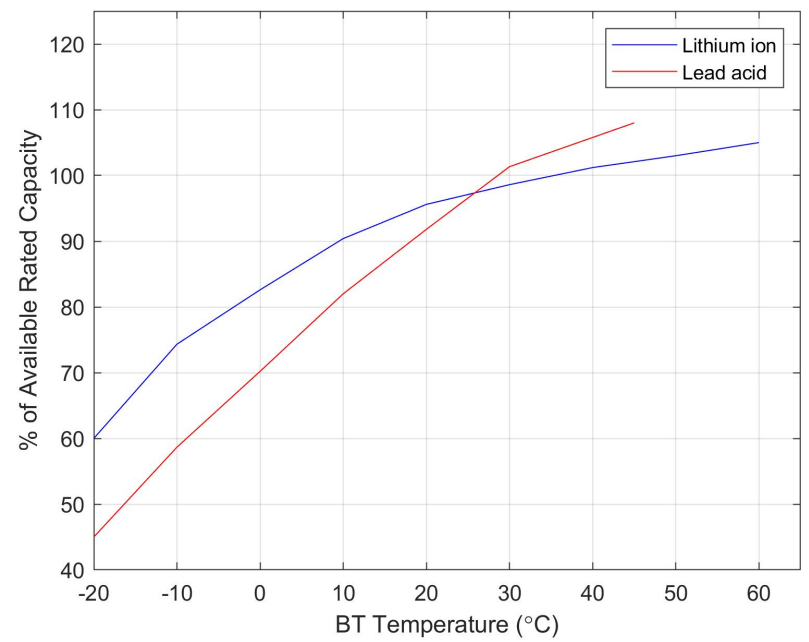

Figure 5: Temperature versus capacity curve of batteries; data extracted from Trojan Battery Company (T-105 with Bayonet Cap model for lead acid [51] and TR 25.6-25 Li-ion model for lithium ion [52]). 
Table 7: Scenarios implemented in the MINES model.

\begin{tabular}{|c|c|c|}
\hline Scenarios & Electricity & Space Heating \\
\hline Scenario 1 & $\begin{array}{l}\text { Home appliances including light- } \\
\text { ing and electric load for DHW }\end{array}$ & $\begin{array}{l}\text { Baseboard Heater at } U=0.5 \\
\mathrm{~W} / \mathrm{m}^{2}-\mathrm{K}\end{array}$ \\
\hline Scenario 2 & $\begin{array}{l}\text { Home appliances including light- } \\
\text { ing and electric load for DHW }\end{array}$ & $\begin{array}{l}\text { Baseboard Heater at } U=0.13 \\
\mathrm{~W} / \mathrm{m}^{2}-\mathrm{K}\end{array}$ \\
\hline Scenario $3^{\mathrm{a}}$ & $\begin{array}{l}\text { Home appliances including light- } \\
\text { ing and electric load for DHW }\end{array}$ & $\begin{array}{l}\text { Baseboard Heater and ASHP at } \\
U=0.13 \mathrm{~W} / \mathrm{m}^{2}-\mathrm{K}\end{array}$ \\
\hline Scenario $4^{\mathrm{b}}$ & $\begin{array}{l}\text { Home appliances including light- } \\
\text { ing and electric load for DHW }\end{array}$ & $\begin{array}{l}\text { Baseboard Heater and ASHP at } \\
U=0.13 \mathrm{~W} / \mathrm{m}^{2}-\mathrm{K}\end{array}$ \\
\hline
\end{tabular}

\subsection{Computational expense and limitation of the proposed model}

The integration of the uncertainty module in the overall modeling framework of MINES demands significant computational requirement in order to get the desired optimization output from the model. For instance, implementing parallel computing, the model implemented in MATLAB ${ }^{\circledR}$ converged to a solution roughly after $30 \mathrm{~h}$ by using 64 -bit operating system, an Intel Core i7-7700HQ $2.800 \mathrm{GHz} 4$-core processor and $16 \mathrm{~GB}$ of RAM. For this reason, this work used state-of-the-art research parallel computing systems from Compute Canada [53] to decrease the computational requirement of the MINES model.

\subsection{Case study input data}

To test the methods described in this section, a case study was conducted for an Indigenous community in the Arctic. Sachs Harbour (Lat: 71.9884 N; Long: 125.23935 W), the Northernmost community in the NWT was selected for this purpose. This community has one of the most extreme winter conditions in Arctic Canada, and thus demonstrates the applicability of the modeling approach to other isolated communities in the region. All of the relevant meteorological information GHI, $u, T_{\text {out }}$ and load demands (electrical and thermal) of the community have been presented in 17 and 35 . The heat load simulation conducted for this study was elaborated by the authors in 17 .

\section{Results and discussion}

This section looks at the uncertainty modeling results generated from the MINES model. The investigation builds from the four scenarios presented in Table 7. The simulated thermal load of Sachs Harbour is assumed to be supplied by electric appliances for domestic hot water (DHW), such as instant water heating devices, and via electric baseboard heaters for space heating demand. Scenarios 3 and 4 use air-source heat pumps (ASHP) instead of the baseboard heater in the first two scenarios. Previous analysis by the authors [17 showed that the ASHP reduced spaced heating load by about $40 \%$ as compared to baseboard heaters. However, the simulation results indicated that load fluctuations caused by the variations of the heat pumps' coefficients of performance negatively impacted the operation of the energy system. In particular, these demand fluctuations resulted in a larger battery storage requirement, along with an increase in overall energy system costs. The authors also looked at the impact of building enclosure improvements as a function of the overall heat transfer coefficient of the building $(U)$. The modeling results suggested that a passive house with an overall $U$ value of $0.13 \mathrm{~W} / \mathrm{m}^{2}-\mathrm{K}$ reduced space heating loads by about $40 \%$ as compared to a normal building. Collectively, scenario 2 was proven to have the best system performance as compared to the other three scenarios in Table 7

\subsection{Deterministic results}

Fig. 6 shows the deterministic full design space and near-optimal Pareto front of scenario 2 after minimizing simultaneously the fuel cons and $L C O E$ of the energy system in question for 


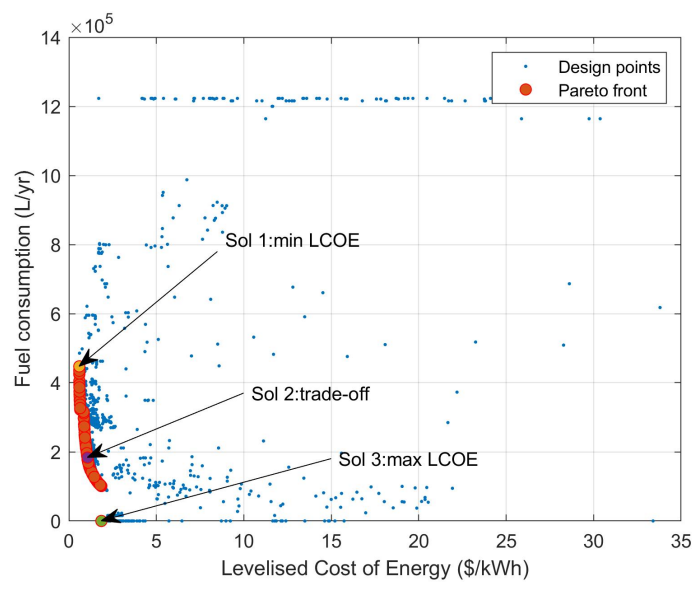

Figure 6: Scenario 2 deterministic results: full design space with the near-optimal Pareto front and the identified solutions of interest.

Sachs Harbour. The respective configurations of the three solutions of interest as specified in the near-optimal Pareto front of Fig. 6 are listed in Table 8 . Solution 1 corresponds to a solution with lowest $L C O E$ and highest $f u e l_{\text {cons }}$. Solution 3, on the other hand, utilizes no back-up DG which led the algorithm to increase the WT capacity of the system. It has a $R E_{\text {pen }}$ of $100 \%$ but also resulted in a larger BT storage capacity to handle mismatch between demand and the RE resource. Consequently, this configuration has the highest $L C O E$ and Life Cycle Cost ${ }^{4}(L C C)$ 54. Solution 2, at the middle of the near-optimal Pareto curve (trade-off point), balances the two solutions mentioned, and includes all the system components of the integrated energy system. Note that the wind resource is able to meet the largest share of demand for the three solutions of interest. This reflects the viability of wind farm projects in the region. The inherent trade-off, however, is the resulting larger BT storage to handle wind's variability. This trade-off analysis is critical in the decision making process of energy system planners and stakeholders.

\subsubsection{Impact of temperature on battery storage performance}

This work extends the deterministic results from [17] by looking at the impact of temperature on BT storage performance considering the thermal properties (Table 6) of both LA and LI batteries. Table 9 shows the simulation performance of two deterministically optimized energy systems with different types of BT storage systems. Note that the identified deterministic optimal capacity of each system component $(\mathrm{PV}, \mathrm{WT}, \mathrm{BT}, \mathrm{DG}, \mathrm{CONV})$ for both configurations (case 1 and 2) were adopted from solution 1 in Table 8 . Case 1, however, uses $\mathrm{LA}$ as its BT storage whereas case 2 uses [L]. The technical and cost parameters of these two comparable storage systems were extracted from HOMER $\mathrm{s}$ database.

Fig. 7 presents hourly performance of $\mathrm{LA}$ and $\mathrm{LI}$. At this stage of the study, the simulation assumed that the BT storage systems are located in a building without thermal management. Using a modified KiBaM model, HOMER tracks the variation of BT capacity in reference to temperature. For example, Fig. 7(b) and (d) shows a decrease in available energy content due to a decrease in operating temperature of the BT (also influenced by the ambient temperature profile of Sachs Harbour). For both storage types, it can be observed that the BT is neither charging nor discharging (Fig. 7) (c) and (e)) whenever the operating BT temperature is outside the temperature ranges specified in Table 9 .

In general, LI performs better than LA batteries. However, this superior performance of LI has a trade-off (in comparison with LA) in reference to the other parameters listed in Table 9 For instance, $\mathrm{LA}$ cost less up-front than $\mathrm{LI}$ but the former's $O \& M$ is more expensive than the latter. Further, the power generated from the back-up DG is relatively high in case 1 (system with LA to compensate the limited amount of battery discharge from LA. This implies higher fuel cons $_{\text {. }}$ and system cost as well. Consequently, this resulted to a cheaper overall system cost, both in

$\sqrt[4]{L C C}$ served as one of the model outputs to represent the sum of the cradle-to-grave economic costs of the integrated energy system for a project lifespan of 25 years. 
Table 8: Deterministic configuration characteristics of the three solutions of interest determined from the nearoptimal Pareto front of Scenario 2.

\begin{tabular}{|c|c|c|c|c|}
\hline \multirow{2}{*}{ Parameter } & \multirow{2}{*}{ Unit } & \multicolumn{3}{|c|}{ Optimization results } \\
\hline & & Sol 1: Min. $L C O E$ & Trade-off Point & Sol 3: Max. $L C O E$ \\
\hline $\mathrm{PV}$ & $\mathrm{kW}$ & $450.45(25.025 \mathrm{~kW} \times 18)$ & $1,725(25 \mathrm{~kW} \times 69)$ & 0 \\
\hline$\overline{\mathrm{WT}}$ & $\mathrm{kW}$ & $570(95 \mathrm{~kW} \times 6)$ & $1,045(95 \mathrm{~kW} \times 11)$ & $3,325(95 \mathrm{~kW} \times 35)$ \\
\hline$\overline{\mathrm{BT}}$ & $\mathrm{kWh}$ & $4,620(9.24 \mathrm{kWh} \times 500)$ & $7,205(55 \mathrm{kWh} \times 131)$ & $7,315(55 \mathrm{kWh} \times 133)$ \\
\hline DG & $\mathrm{kW}$ & $675(225 \mathrm{~kW} \times 3)$ & $675(225 \mathrm{~kW} \times 3)$ & 0 \\
\hline CONV & $\mathrm{kW}$ & $600(200 \mathrm{~kW} \times 3)$ & $800(200 \mathrm{~kW} \times 4)$ & $800(200 \mathrm{~kW} \times 4)$ \\
\hline Strategy & - & LFOS & LFOS & LFOS \\
\hline$P_{p v}$ & $\mathrm{kWh}$ & 414,407 & $1,405,135$ & 0 \\
\hline$P_{w}$ & $\mathrm{kWh}$ & $2,456,400$ & $4,531,567$ & $14,418,623$ \\
\hline$\overline{P_{B T}, \text { out }}$ & $\mathrm{kWh}$ & $151,831.41$ & 365,881 & 513,951 \\
\hline \begin{tabular}{|l|l}
$P_{D G}$ \\
\end{tabular} & $\mathrm{kWh}$ & $1,272,995$ & 529,758 & 0 \\
\hline LPSP & $\%$ & 0 & 0 & 0 \\
\hline$R E_{\text {pen }}$ & $\%$ & 69.27 & 91.81 & 100 \\
\hline $\overrightarrow{P_{\text {excess }}}$ & $\%$ & 15.19 & 4.93 & 1.05 \\
\hline fuel ${ }_{\text {cons }}$ & $\mathrm{L} / \mathrm{yr}$ & 447,470 & 183,595 & 0 \\
\hline $\mathrm{CO}_{2}{ }^{2}$ & $\mathrm{tCO}$ & 2,096 & 1,523 & 757 \\
\hline$C C$ & $\begin{array}{l}\text { 2-eq/yr } \\
\text { CND } \$\end{array}$ & $15,117,673$ & $37,839,517$ & $79,936,645$ \\
\hline$\angle C O E$ & CND & 0.59387 & 1.06348 & 1.85487 \\
\hline & $\$ / \mathrm{kWh}$ & & & \\
\hline$L C C$ & CND $\$$ & $35,756,756$ & $64,031,794$ & $111,681,201$ \\
\hline
\end{tabular}

${ }^{\text {a }}$ Lifecycle $\mathrm{CO}_{2}$ emissions of the energy system

Table 9: Performance of lead acid and lithium ion batteries as applied to integrated energy system.

\begin{tabular}{|c|c|c|c|}
\hline Parameter & Unit & $\begin{array}{l}\text { Case 1: System } \\
\text { with LA }\end{array}$ & $\begin{array}{l}\text { Case 2: System } \\
\text { with LI }\end{array}$ \\
\hline BT max temp & ${ }^{\circ} \mathrm{C}$ & 55 & 45 \\
\hline BT min temp & ${ }^{\circ} \mathrm{C}$ & -20 & -20 \\
\hline$C C_{B T}$ & CND $\$$ & $1,345,500$ & $1,840,916$ \\
\hline$O \& M_{B T}$ & $\mathrm{CND} \$$ & 797,439 & 644,352 \\
\hline$\overline{P_{p v}}$ & $\mathrm{kWh}$ & 506,195 & 506,195 \\
\hline$\overline{P P_{w}}$ & $\mathrm{kWh}$ & $2,475,542$ & $2,475,542$ \\
\hline P每 & $\mathrm{kWh}$ & 73,897 & 118,806 \\
\hline$\overline{P_{B T, i n}}$ & $\mathrm{kWh}$ & 87,465 & 127,243 \\
\hline \begin{tabular}{|l|}
$P_{D G}$ \\
\end{tabular} & $\mathrm{kWh}$ & $1,331,850$ & $1,280,713$ \\
\hline LPSP & $\%$ & 0 & 0 \\
\hline$\overline{R E_{\text {pen }}}$ & $\%$ & 60.7 & 62.2 \\
\hline fuel ${ }_{\text {cons }}$ & $\mathrm{L} / \mathrm{yr}$ & 528,472 & 506,491 \\
\hline System $C C$ & CND $\$$ & $16,575,414$ & $17,070,830$ \\
\hline$\angle C O E$ & CND & 0.6659 & 0.6784 \\
\hline & $\$ / \mathrm{kWh}$ & & \\
\hline$L C C$ & CND $\$$ & $40,092,700$ & $40,846,160$ \\
\hline
\end{tabular}


terms of $L C O E$ and $L C C$. Note, however, that this result is heavily influenced by the BT storage data extracted from HOMER $\mathrm{s}$ database, and LA might also be a better option depending on its operating temperature range.
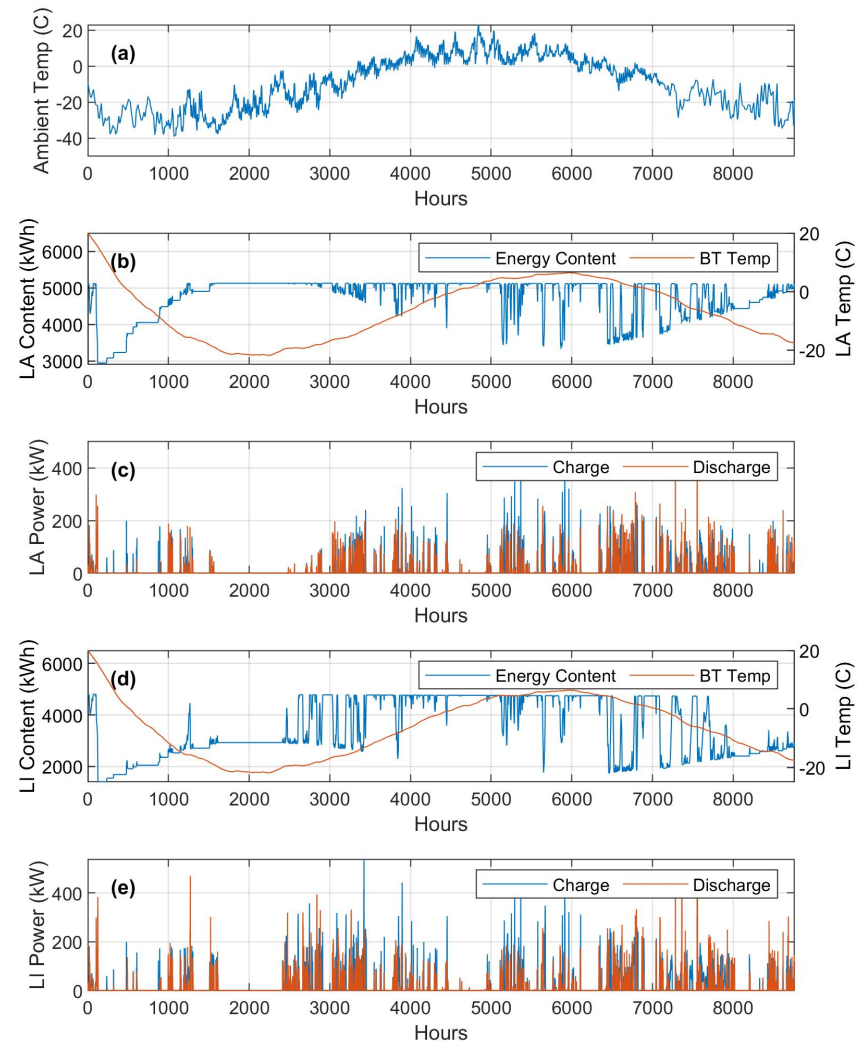

Figure 7: Example deterministic simulation results when there is no thermal management in a building where the battery storage systems are located: (a) ambient temperature of Sachs Harbour; (b) Energy content and operating temperature of lead acid BT; (c) Charge-discharge of lead acid BT; (d) Energy content and operating temperature of lithium ion BT; (c) Charge-discharge of lithium ion BT.

This section demonstrates the negative impact of installing BT storage systems in a building without thermal management. To depict real-world situations in this study and to improve the system performance of the overall integrated energy systems in Fig. 2, the robust optimization assumes that the BT storage is located in a temperature-controlled building in Sachs Harbour. A controlled temperature environment for batteries is also recommended by BT manufacturers such as Trojan [51].

\subsection{Stochastic simulation results}

In comparison with the sensitivity evaluation used in the author's previous study [17, this work carries out a probabilistic analysis using the two types of uncertainty introduced in the model (Section 2.3). This approach was first applied to the deterministic solution of scenario 2 -solution 1 to test statistical convergence for an individual use case.

Fig. 8 presents a series of probability distribution functions that corresponds to various technical, economic and environmental outputs that can be extracted from the MINES model for a risk-seeking stakeholder or decision maker. For example, solution 1 of scenario 2 has a mean $R E_{\text {pen }}$ of approximately 51\% after simulating 1000 times probabilistically as compared to its initial deterministic $R E_{\text {pen }}$ of $69.27 \%$. It can be observed that due to the uncertainties introduced in the model, the overall power generation from $R E$ was reduced. This $R E_{\text {pen }}$ is even lower when the risk preference shifts from risk seeking to risk averse. Consequently, the mean $f u e l_{\text {cons }}$ of the DG increased to approximately $750,000 \mathrm{~L} / \mathrm{yr}$ as compared to its initial deterministic value of 447,470 
L/yr. This reflects that the DG was under-sized when multiple overlapping uncertainties were 415 introduced in the model.
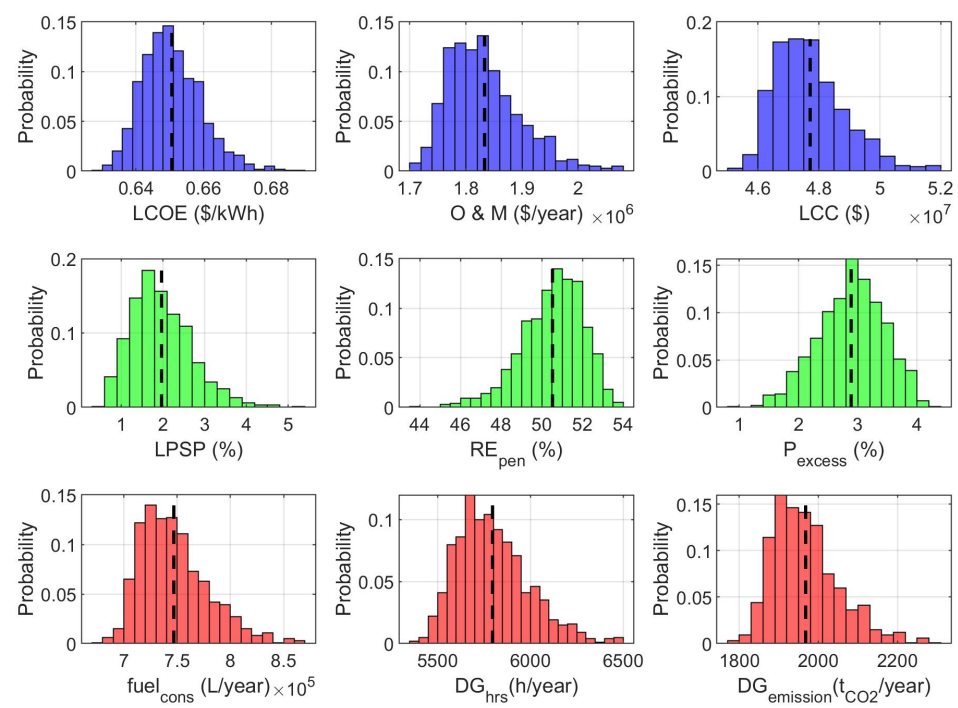

Figure 8: Risk seeking scenario 2-solution 1 series of probability distribution functions generated probabilistically using 1000 samples; dashed line refers to mean value.

Fig. 9 shows the mean $R E_{\text {pen }}$ decreases to approximately $20 \%$ when the preference of the

decision maker towards uncertainty shifts from being risk seeking to risk averse. The meanffuel cons, on the other hand, were further increased from approximately $750,000 \mathrm{~L} / \mathrm{yr}$ (risk seeking) to $1,400,000 \mathrm{~L} / \mathrm{yr}$ (risk averse). This implies increase in system costs $[L C O E, O \& M, L C C)$ to ensure robust performance of the energy system under worst case realization of the uncertainties. Specifically, this is attributable the highest increment (in comparison with the other risk coefficients listed in Table 4) in energy demand and the reduction in the other uncertain variables (renewable resources and temperature).
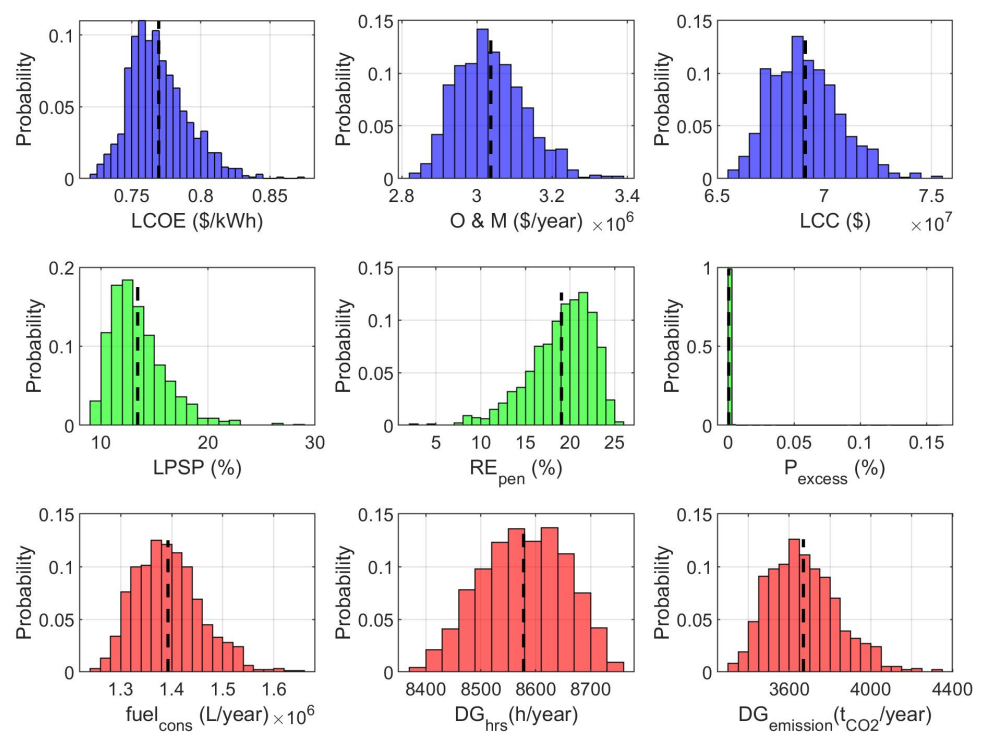

Figure 9: Risk averse scenario 2-solution 1 series of probability distribution functions generated probabilistically using 1000 samples; dashed line refers to mean value.

A comparative analysis for the three solutions of interest in scenario 2 considering risk seeking 
preference of the decision maker and the probabilistic results of their respective $L C O E$ and $L P S P$ values are shown Fig. 10. In the presence of uncertainties, $L P S P$ of solution 3 is approximately $12 \%$ (mean) as this energy system configuration has no back-up DG. Hence, this solution is not resilient to extreme temperature events or any increase in energy demand in Sachs Harbour. The opposite can be observed for both solutions 1 and 2 wherein $675 \mathrm{~kW}$ capacity of DG are available (Table 8). This shows the critical role of $\overline{D G}$ to be able to maintain an $L P S P$ of approximately $1 \%-2 \%$ (mean) for both solutions. Further, this also implies that the constraint formulation of $0 \%$ LPSP (Eq. 4) will be slightly violated (solutions 1 and 2) when multiple overlapping uncertainties are considered. Note that the probabilistic simulations done so far were taken from the deterministic optimization results, and hence, a separate robust optimization run will be performed in MINES wherein full compliance to the constraints formulation will be strictly observed. Fig. 10 also shows the range of $L C O E$ values with their respective probability once the $L P S P$ deviates from $0 \%$ (deterministic value across all solutions).

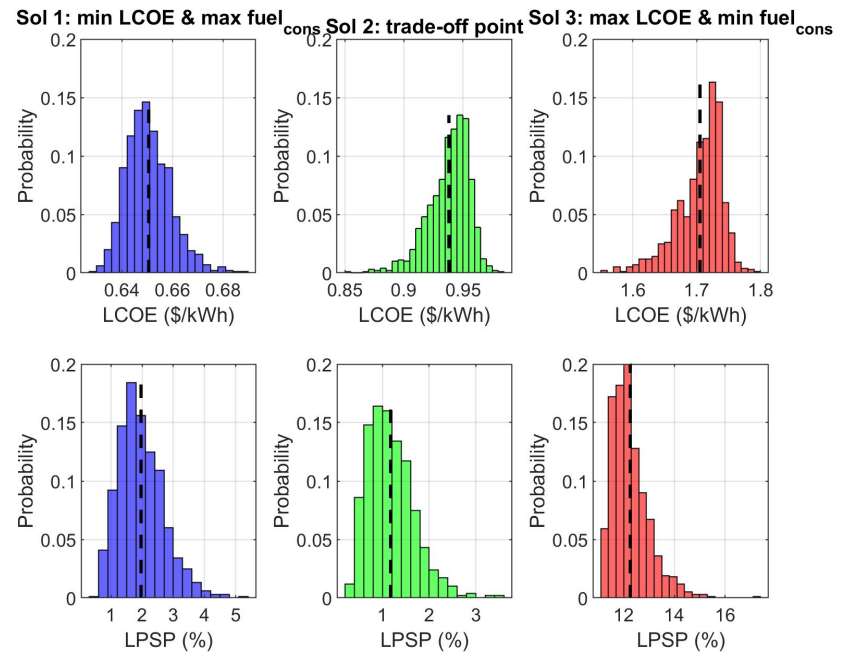

Figure 10: Risk seeking scenario 2 probabilistic simulations for the three solutions of interest generated from the deterministic optimization results; dashed line refers to mean value.

The hourly dispatch for solution 1 assuming risk seeking preference of the decision maker towards uncertainty is shown in Fig. 11. The hourly mean values of each source of energy is illustrated together with its variations due to uncertainties. For solutions where all system components are available, $\mathrm{RE}$ is treated as a priority dispatch before discharging available power from the $\mathrm{BT}$ storage and DG. Hence, a significant variation in power output from the DG (solution 1) can be observed as influenced by the multiple overlapping uncertainties introduced in the model. The lower bound of each hourly variation of the power output coming from the DG was affected by the $30 \% D G_{L F}$ constraint to avoid damaging the generator by running at very low partial loads.

\subsection{Robust optimization results}

A comparison of the near-optimal Pareto fronts generated deterministically (DT) and through the robust optimization process for scenario 2 considering risk attitudes of decision maker towards uncertainty are presented in Fig. 12. The non-deterministic solution was obtained using the same GA parameters listed in Table 2. Further, the last generation obtained from the deterministic algorithm of the MINES model was used as the first generation of the RO optimization. Doing this, along with parallel computing results in a relatively faster rate of convergence in obtaining the desired robust optimal capacities of the system components and the corresponding dispatch strategy for the integrated energy system.

It can be observed that the near-optimal Pareto front tends to shift towards higher objective function values when the algorithm changed from $\mathrm{DT}$ to $\mathrm{RO}$. This deviation implies higher $L C O E$ for the system when uncertainties were incorporated in the model. In comparison with the DT optimal solutions, Table 10 shows an increase in the optimal capacity for majority of the system components $\mathrm{WT}, \mathrm{PV}, \mathrm{DG}, \mathrm{CONV}$ except the $\mathrm{BT}$ storage. In the presence of uncertainties, this suggests that the $\mathrm{RO}$ algorithm assigns its preference to generate power from the $\mathrm{DG}$ over 


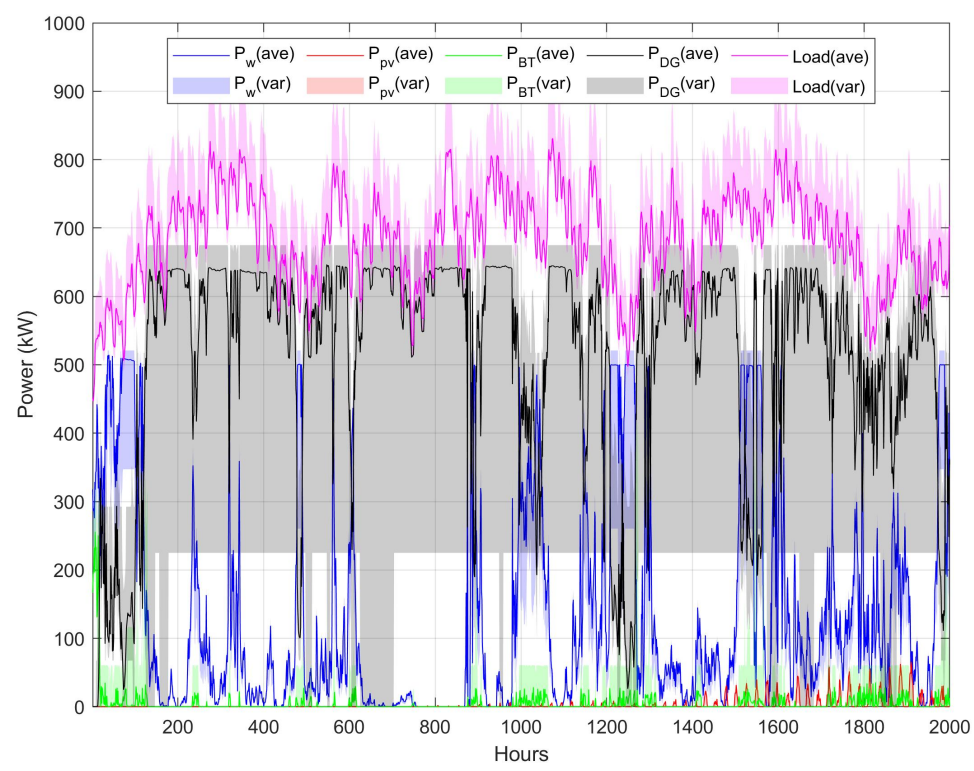

Figure 11: Hourly average (ave) and variation (var) of the deterministic optimal configuration in scenario 2 that was simulated probabilistically; assumed risk seeking preference of the decision maker.

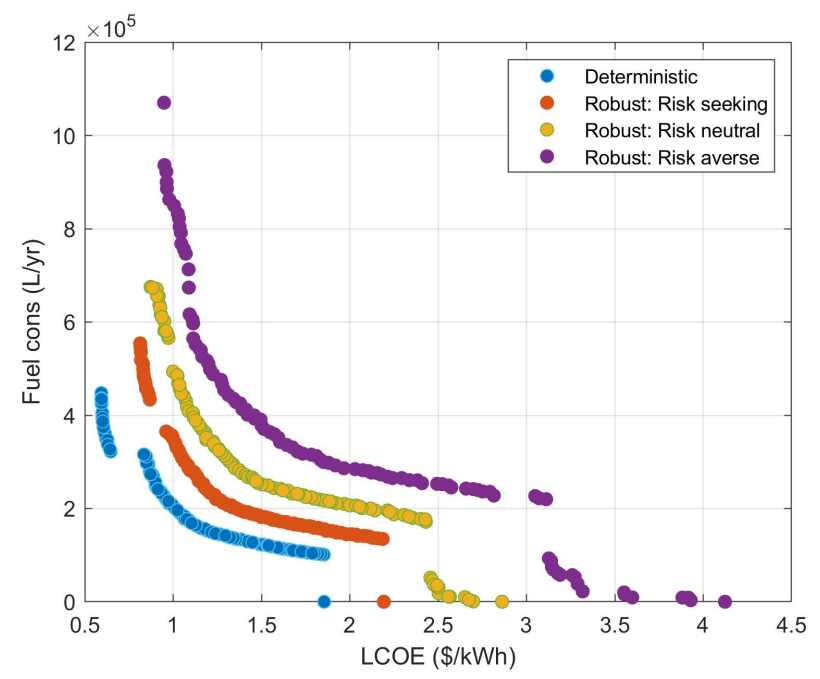

Figure 12: Scenario 2 near-optimal Pareto front comparison for deterministic and robust optimization results with specific risk preferences.

discharging the BT storage to meet load deficit. This is influenced by the charge-discharge cycles of the BT storage which is also affected by the renewables (wind and solar), treated as uncertain paremeters for this work. Hence, DG offers more flexibility whenever there is load deficit in the energy system. This result is critical for consideration among remote communities like Sachs Harbour wherein fuels are being delivered via barge once a year since year-round road access is not available.

The risk attitudes of the decision maker towards uncertainty were observed to impact the optimal component capacities of the integrated energy system. As shown in Table 10, an increase in the component capacity implies higher system $L C O E$ and fuel $_{\text {cons }}$ from being risk seeking to risk averse across the three solutions of interest. This also reflects that the goal of having a robust energy system that can operate under extreme climate conditions has to be balanced with the possible implications of having an increased energy system $L C O E$ and fuel $_{\text {cons }}$. The increase in $\mathrm{fuel}_{\text {cons }}$ is attributable to the uncertainties incorporated in the solar irradiance and wind speed of Sachs Harbour, ensuring that the load would still be met in spite of the randomness (uncertainty) 
of renewable resources.

\subsection{Policy recommendations}

Huntington et al. [55] argued that the purpose of energy modeling is to produce insights and not just numbers. Hence, this section provides insights and recommendations based on the outputs presented in Section 3 and the overall modeling framework described in Section 2 .

\subsubsection{Multiple viable energy system configurations}

Model insight: The results presented from the modeling work carried out for Sachs Harbour indicate that multiple energy system configurations were found to be viable in the North even in the presence of uncertainties. Specifically, Table 8 shows that wind can meet the largest share of the energy demand for the community, and this reflects that wind is a viable energy resource for remote communities in Northern Canada. Other system configurations were found to be feasible but with different levels of renewable energy penetration and capacities from back-up sources of energy such as BT storage and DG. Fig. 12 also shows that the risk preferences of decision makers towards uncertainties were also proven to impact the optimal configuration of the integrated energy system.

Policy recommendation: The first recommendation of this research is to develop a documented IPP policy in the NWT considering the feasibility of multiple renewables-based energy system in the Arctic. Note that power generation in Sachs Harbour is fully owned and operated by the Crown utility, Northwest Territories Power Corporation (NTPC). This is also the case for all Indigenous remote communities across the three territories in Northern Canada. Hence, building a renewable energy project, without a documented IPP policy in a region where there is a Crown utility, will be challenging since the majority of electric utilities worldwide, either publicly or privately owned, are regulated by utilities commission or public utilities board. For example, previous wind farm feasibility studies [56] have been conducted in Sachs Harbour but none of the projects were realized because of the lack of an explicit energy policy that supports renewable energy infrastructure development.

\subsubsection{Community-specific (levelised) cost of energy}

Model insight: Table 8 shows the $L C O E$ for the three solutions of interest identified in Fig. 6. Table 10, on the other hand, presents $[\angle C O E$ for the the three solutions of interest in the presence of uncertainties while taking into account varying risk preferences of the decision maker. The modeling results show that the cost of energy varies depending on the configuration of the integrated energy system, and is influenced by the amount of energy specific for the community of Sachs Harbour. MINES can handle different communities to calculate community-specific levelised cost of energy in the North or remote communities in general.

Policy recommendation: The second policy recommendation of this work is to re-assess the pricing structure in determining the applicable PPA rates as outlined in a certain IPP policy. Specifically, the community-specific $L C O E$, as shown in the modeling work of this research, should be recognized in awarding $\mathrm{PPA}$ contracts for renewable energy developers. As of writing, for example, the Qulliq Energy Corporation (QEC) is applying to the Utility Rates Review Council (URRC) of Nunavut to have a territory-wide flat PPA rate of $\$ 0.25$ per $\mathrm{kWh}$ based on their proposed IPP policy [57. The proposed rate is based on the average diesel fuel costs in the territory. This pricing structure proposed by QEC to the URRC will be a disadvantage to many renewable project proponents in areas where diesel fuel costs are higher.

\subsubsection{Access to capital and transformational collaboration between stakeholders}

Model insight: The modeling framework described in this work shows that trade-off analysis is critical in determining the vast range of potential energy solutions generated by the MINES model. In particular, it was shown in Fig. 12 that an increase in $L C O E$ is the inherent trade-off resulting from reducing diesel fuel $_{\text {cons }}$ of the integrated energy system due to the introduction of variable $\mathrm{RE}$ and BT storage. As shown in Table 10, this increase in $L C O E$ is significant when uncertainties and risk preferences of decision makers are introduced into the model. The other costs increases, in conjunction with the $L C O E$ is associated with the $C C$ of the system.

Policy recommendation: Primarily, one of the main barriers for the transition of Indigenous communities towards clean and sustainable sources of energy is a lack of access to capital investments. At the moment, the First Nations Power Authority is the only North-American non-profit 


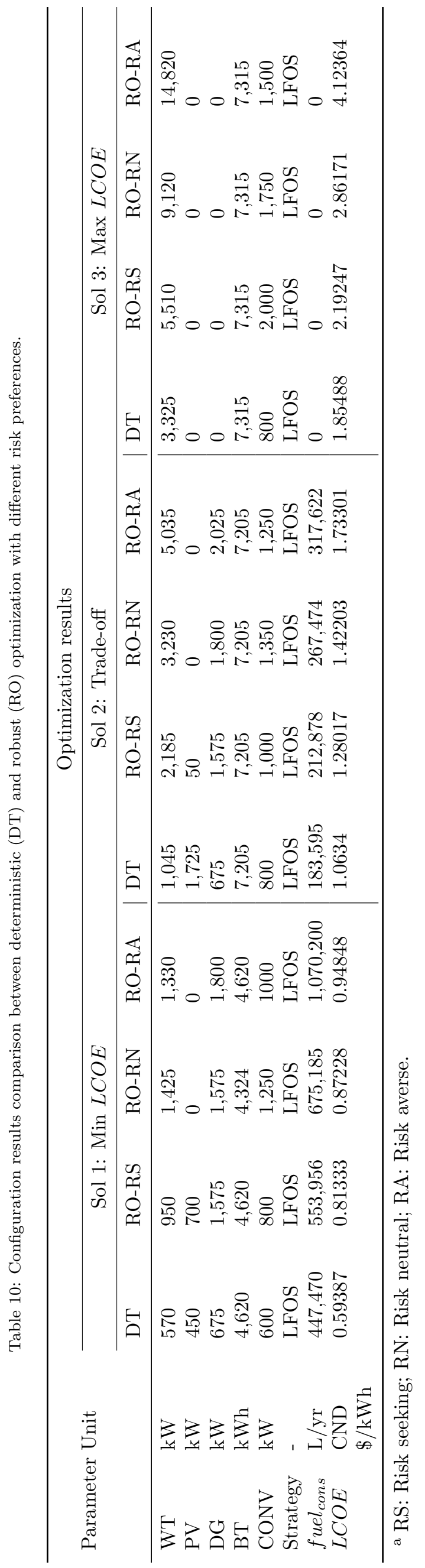


Indigenous owned and controlled organization developing power projects with Indigenous peoples 58. Hence, this work recommends specific stipulations in the IPP policy on how to leverage capital investments for Indigenous peoples-led energy projects. Specifically, community partnerships with industry, utilities, and governments should be strengthened moving forward. These partnerships should include majority stake for Indigenous communities as this enables Indigenous stakeholders to influence distribution, re-investment and future planning [59. This tie-up leads to mutual benefits for all parties as the respective partners have the support from the Indigenous peoples who have the land base. Ultimately, such partnerships also represent a significant step towards economic reconciliation where Indigenous peoples are not just participants but key players and partners in the mainstream economy.

\subsubsection{Renewable energy integration limits}

Model insight: Integrating renewables in the current electricity grid of remote communities in the North requires a grid impact study from the Crown utility. Although there is an increase in renewable energy penetration for remote communities, stability of the grid to deliver reliable power to the community, especially to those which are most isolated, should be ensured. For instance, Sachs Harbour's solution 1 of scenario 2 has a mean $R E_{p e n}$ of approximately $51 \%$ after simulating probabilistically (considering risk seeking preference of the decision maker) while its initial deterministic $R E_{p e n}$ is $69.27 \%$. This significant integration of intermittent renewables would be likely to cause stability and reliability issues if not properly addressed.

Policy recommendation: With the modeling results generated from MINES, this research recommends for NTPC to consider suitable BT storage systems in order to increase renewable energy integration limits in the NWT As shown in Table 9 and Fig. 7, it is also critical to consider the impact of temperature on BT capacity given the long and cold winters in the Arctic. The BT storage system can also be integrated in the net metering systems of the territory. This would enable residents/communities to store some of the power generated locally rather than selling everything back to the Crown utility. This set-up might potentially address grid reliability issues caused by the intermittency of renewables as well.

\subsubsection{Demand-side energy solutions}

Model insight: This work points out that a $40 \%$ space heating load reduction can be obtained when the overall $U$ value of the building enclosure is $0.13 \mathrm{~W} / \mathrm{m}^{2}-\mathrm{K}$ (equivalent to passive house performance).

Policy recommendation: According to the National Energy Board 60, energy costs are a major contributor to the high cost of living in the North, with per capita of energy use being twice the Canadian average. Hence, this work recommends that accelerating energy transitions in Arctic remote communities should be taken from a holistic perspective wherein energy solutions are not limited to the supply-side aspects but also to demand-side considerations. In particular, this work recommends evaluating building enclosure improvements especially in public housing among remote communities in the Northern territories. This does not only provide reductions in space heating loads but also offers non-energy benefits such as thermal comfort and increased resiliency in extreme temperature events. Supply-side energy solutions such as renewable energy integration is beneficial in meeting decarbonization goals, but they are generally expensive to implement. Thus, this research recommends policies that promote energy conservation and efficiency initiatives for the community. Aside from the ones in place right now in the NWT (Section 1.1.1), there should be a strict implementation of high-performance building standards in the region as prescribed by the International Passive House Institute [61.

\section{Conclusions}

The energy modeling framework presented in this work evaluates trade-offs and balances risk hedging strategies in integrated energy systems planning. The risk preferences of decision makers towards uncertainty was found to influence the optimal capacity of the integrated energy system. Specifically, the near-optimal Pareto front from the deterministic optimization tends towards higher optimal objective function values when the algorithm shifts to robust optimization which endogenises multiple overlapping uncertainties. This implies that the optimal capacities found deterministically were under-dimensioned considering possible increments and reductions from the load and other meteorological parameters relevant for Sachs Harbour. Uncertainties relating to 
system reliability were also proven to be critical in ensuring that the energy system will operate even in extreme climate conditions.

It was observed from one of the solutions of interest that due to uncertainties incorporated in the energy model, the deterministic $R E_{\text {pen }}$ of $69.27 \%$ dropped to around $51 \%$ (mean) after simulating probabilistically. Conversely, the deterministic fuel $_{\text {cons }}$ of $447,470 \mathrm{~L} / \mathrm{yr}$ increased to $750,000 \mathrm{~L} / \mathrm{yr}$ (mean) to compensate for the reduced operation of the renewables. To ensure robust performance of the energy system under worst-case realization of uncertainties, increase in component capacity and the overall system costs $[L C O E, L C C, C C$ ) were demonstrated as the attitude of the decision maker shifts from being risk seeking to risk averse.

The probabilistic algorithm assigns its preference to the diesel generator over the battery storage whenever there is a load deficit in the system. This is due to the latter's charge-discharge cycling behavior being influenced by the amount of excess and deficit from the renewables, while the former's power can be dispatched promptly. An inherent trade-off, however, is the increase in environmental emissions from diesel generation to compensate for the unavailability or limited power being dispatched from the renewables and battery storage.

Real-world applications of the generic modeling approaches are described, while taking into account holistic energy solutions. The method and results are applicable not just for the Canadian Arctic region, but remote communities globally that all have similar issues with diesel avoidance. In particular, achieving decarbonization targets while ensuring affordable energy costs for remote communities is possible given robust policies that can accelerate and support the energy transition towards more sustainable energy outcomes. Synergies between stakeholders (local governments, private sectors, utility corporations and Indigenous peoples) are also highlighted to be fundamental in achieving the desired energy transition for remote communities.

\section{Future work}

The uncertainty module of MINES will be further improved by exploring autocorrelation to examine dependencies between uncertain variables. Adding new technologies in the proposed energy system model is also valuable. For example, solar thermal and heat storage can be included in the modeling analysis done for remote Arctic communities. The thermal effects on electricity battery storage will be incorporated in the actual optimization algorithm, and higher computational resource from Compute Canada will be explored to perform this work. Finally, the quantitative outputs from the energy model will be adapted to lower latitude communities to synthesize effective policy recommendations even outside the Canadian Arctic region.

\section{Acknowledgement}

Funding for this work was provided by Polar Knowledge Canada and the Marine Environmental Observation, Prediction and Response Network (MEOPAR). Authors would also like to acknowledge support from the Government of Northwest Territories and Northwest Territories Power Corporation by providing actual electrical load and wind data which served as vital inputs for the project. Marvin Quitoras would also like to acknowledge financial support from MITACS during his research stay in the UK. Financial and other logistical support from World Wildlife Fund are also recognized.

\section{Appendix A. Sequential Monte Carlo state duration sampling}

This appendix provides an overview on relevant steps needed to generate the outage history on each component of the energy system using the sequential Monte Carlo state duration sampling method.

In a two-state component representation, the distribution functions introduced by Billinton and Li [47. refer to the operating (uptime) and repair (downtime) state of a system component i, and are usually assumed to be exponential. This can be summarized in the following steps:

- Step 1: Identify initial state of energy system component (ii). Generally, all components are assumed to be operational at least in the first hour. Following the initial state, let $\tau_{i}$ denote 
the state of the $i$ th component:

$$
\tau_{i}(t)= \begin{cases}0 & \text { if downstate } \\ 1 & \text { if upstate }\end{cases}
$$

- Step 2: Sample the state duration of each component il depending on its present state. For instance, given an exponential distribution, the sampling value of the state duration can be expressed as:

$$
\begin{gathered}
\text { Upstate }_{i}=\text { round }(\overbrace{-\frac{1}{\lambda_{f i}}}^{\mathrm{MTBF}} \times \ln \left(U_{i}\right)) \\
\text { Downstate }_{i}=\text { ceil }(\underbrace{-\frac{1}{\lambda_{\text {ri }}}}_{\text {MTTR }} \times \ln \left(U_{i}\right))
\end{gathered}
$$

where $U_{i}$ is a uniformly distributed number between $[0,1]$ corresponding to the $i$ th component. If the present state is the down state, $\lambda_{r i}$ will be the repair state of the $i$ th component $(1 / \mathrm{h})$ (the annotated term in Eq. A.3 is called Mean Time To Repair $\left(M T T R_{i}\right.$ 62])). The round function of MATLAB ${ }^{\circledR}$ was used to round Upstate $_{i}$ to its nearest decimal or integer. If the present state is the up state, $\lambda_{f i}$ will then be the failure rate of the $i$ th component $(1 / \mathrm{h})$ (the annotated term in Eq. A.2 is called Mean Time Between Failure $\left(M T B F_{i}[62)\right)$. The ceil function of MATLAB ${ }^{\circledR}$ was used to round Downstate $_{i}$ to its nearest integer greater than or equal to its value. Table A.11 shows the uncertainty parameters used to generate outage history for each component i of the energy system.

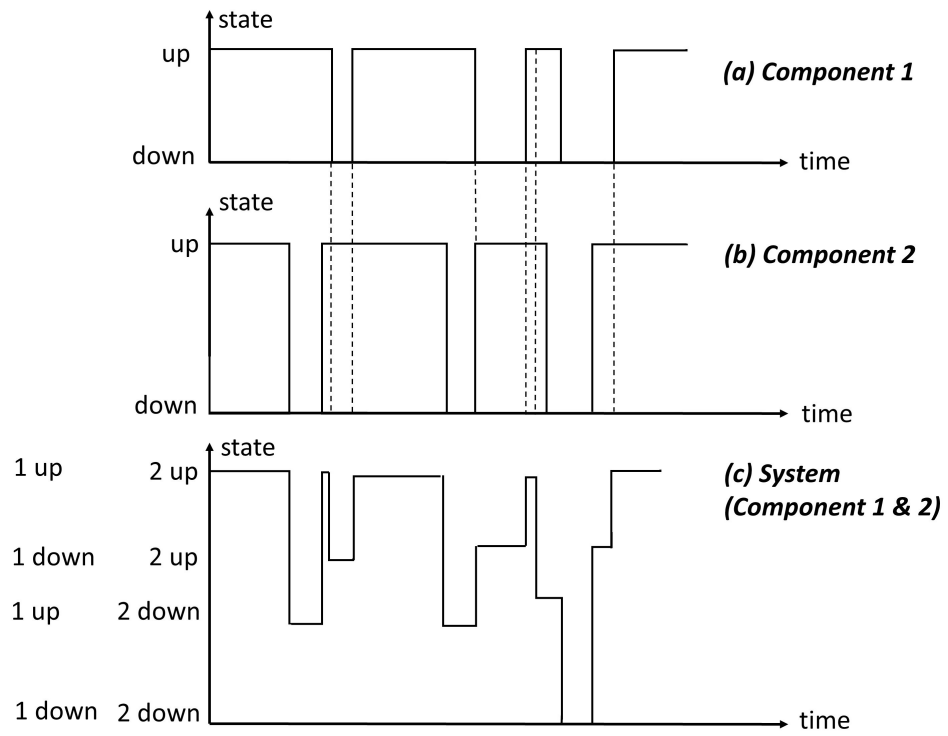

Figure A.13: Chronological component state transition process of each component ( $\mathrm{a}$ and $\mathrm{b}$ ) and the overall system (c); adapted from 47.

- Step 3: Repeat Step 2 for each hour $(1$ - 8760) in the model, and record sampling values of each state duration for all components. A graphical representation of example chronological component state transition can be seen in Fig. A.13(a) and (b).

- Step 4: As shown in Fig. A.13(c), the chronological state transition of the overall system can then be obtained by combining the chronological component state transition processes for both components 1 and 2 (Eq. A.4.

$$
\tau_{\text {system }}(t)=\sum \tau_{i}(t)
$$


Table A.11: Uncertainty parameters to generate outage history for each component of the energy system; approach was adapted from [47] and actual values were taken from [62].

\begin{tabular}{|c|c|c|}
\hline Parameter & Value & Unit \\
\hline$M T B F_{P V}$ & 2190 & hours \\
\hline$\overline{M T T R_{P V}}$ & 80 & hours \\
\hline$\overline{M T B F_{W T}}$ & 1,920 & hours \\
\hline$\overline{M T T R_{W T}}$ & 80 & hours \\
\hline$\overline{M T B F_{D G}}$ & 950 & hours \\
\hline$\overline{M T T R_{D G}}$ & 50 & hours \\
\hline$M T B F_{C O N V}$ & 87,600 & hours \\
\hline$\overline{M T T R_{C O N V}}$ & 80 & hours \\
\hline
\end{tabular}

\section{References}

[1] V. Krey, K. Riahi, Risk Hedging Strategies under Energy System and Climate Policy Uncertainties, Technical Report August, International Institute forApplied Systems Analysis, Laxenburg, Austria, 2009.

[2] S. Pye, N. Sabio, N. Strachan, An integrated systematic analysis of uncertainties in UK energy transition pathways, Energy Policy 87 (2015) 673-684.

[3] A. A. M. H. A. Asbahi, F. Z. Gang, W. Iqbal, Q. Abass, M. Mohsin, R. Iram, Novel approach of Principal Component Analysis method to assess the national energy performance via Energy Trilemma Index, Energy Reports 5 (2019) 704-713.

[4] D. Heerema, D. Lovekin, Power Shift in Remote Indigenous Communities A cross-Canada scan of diesel reduction and clean energy policies, Technical Report July, 2019. URL: www. pembina.org.

[5] Energy and Mines Ministers Conference, Clean Technology Integration in Remote Communities: Policies, Programs, and Initiatives by Federal, Provincial, and Territorial Governments, Technical Report August, 2018.

[6] D. Lovekin, B. Dronkers, B. Thibault, Power purchase policies for remote Indigenous communities in Canada: Research on government policies to support renewable energy projects, Technical Report, World Wildlife Fund, Pembina Institute, 2016.

[7] W. Usher, N. Strachan, Critical mid-term uncertainties in long-term decarbonisation pathways, Energy Policy 41 (2012) 433-444.

[8] S. Pfenninger, A. Hawkes, J. Keirstead, Energy systems modeling for twenty-first century energy challenges, Renewable and Sustainable Energy Reviews 33 (2014) 74-86.

[9] G. Mavromatidis, K. Orehounig, J. Carmeliet, Comparison of alternative decision-making criteria in a two-stage stochastic program for the design of distributed energy systems under uncertainty, Energy 156 (2018) 709-724.

[10] C. Hamarat, J. H. Kwakkel, E. Pruyt, E. T. Loonen, An exploratory approach for adaptive policymaking by using multi-objective robust optimization, Simulation Modelling Practice and Theory 46 (2014) 25-39.

[11] D. E. Majewski, M. Wirtz, M. Lampe, A. Bardow, Robust multi-objective optimization for sustainable design of distributed energy supply systems, Computers and Chemical Engineering 102 (2017) 26-39.

[12] K. Deb, S. Gupta, D. Daum, J. Branke, A. K. Mall, D. Padmanabhan, Reliability-based optimization using evolutionary algorithms, IEEE Transactions on Evolutionary Computation 13 (2009) 1054-1074.

[13] C. E. Clark, B. DuPont, Reliability-based design optimization in offshore renewable energy systems, Renewable and Sustainable Energy Reviews 97 (2018) 390-400. 
[14] L. Chu, Reliability Based Optimization with Metaheuristic Algorithms and Latin Hypercube Sampling Based Surrogate Models, Applied and Computational Mathematics 4 (2015) 462.

[15] M. A. Valdebenito, G. I. Schuëller, A survey on approaches for reliability-based optimization, Structural and Multidisciplinary Optimization 42 (2010) 645-663.

[16] H. K. Ringkjøb, P. M. Haugan, A. Nybø, Transitioning remote Arctic settlements to renewable energy systems - A modelling study of Longyearbyen, Svalbard, Applied Energy 258 (2020) 114079.

[17] M. R. Quitoras, P. Elia, P. Rowley, C. Crawford, Remote community integrated energy system optimization including building enclosure improvements and quantitative energy trilemma metrics, Applied Energy 267 (2020) 115017.

[18] K. Deb, A. Member, A. Pratap, S. Agarwal, T. Meyarivan, A fast and elitist multi-objective genetic algorithm:NSGAII 6 (2002) 182-197.

[19] R. Evins, P. Pointer, R. Vaidyanathan, S. Burgess, A case study exploring regulated energy use in domestic buildings using design-of-experiments and multi-objective optimisation, Building and Environment 54 (2012) 126-136.

[20] Y. Zhang, P. E. Campana, A. Lundblad, J. Yan, Comparative study of hydrogen storage and battery storage in grid connected photovoltaic system : Storage sizing and rule-based operation q, Applied Energy 201 (2017) 397-411.

[21] J. Forde, C. J. Hopfe, R. S. McLeod, R. Evins, Temporal optimization for affordable and resilient Passivhaus dwellings in the social housing sector, Applied Energy 261 (2020) 114383.

[22] H. G. Beyer, B. Sendhoff, Robust optimization - A comprehensive survey, Computer Methods in Applied Mechanics and Engineering 196 (2007) 3190-3218.

[23] F. S. Gazijahani, J. Salehi, Robust Design of Microgrids with Reconfigurable Topology under Severe Uncertainty, IEEE Transactions on Sustainable Energy 9 (2018) 559-569.

[24] G. Petrone, J. Axerio-Cilies, D. Quagliarella, G. Iaccarino, A probabilistic non-dominated sorting ga for optimization under uncertainty, Engineering Computations (Swansea, Wales) 30 (2013) 1054-1085.

[25] E. K. Doolittle, H. L. Kerivin, M. M. Wiecek, Robust multiobjective optimization with application to Internet routing, Annals of Operations Research 271 (2018) 487-525.

[26] Z. Tang, J. Périaux, G. Bugeda, E. Oñate, Lift maximization with uncertainties for the optimization of high lift devices using multi-criterion evolutionary algorithms, 2009 IEEE Congress on Evolutionary Computation, CEC 2009 (2009) 2324-2331.

[27] J. W. Herrmann, A genetic algorithm for minimax optimization problems, Proceedings of the 1999 Congress on Evolutionary Computation, CEC 19992 (1999) 1099-1103.

[28] W. Chen, J. Unkelbach, A. Trofimov, T. Madden, H. Kooy, T. Bortfeld, D. Craft, Including robustness in multi-criteria optimization for intensity-modulated proton therapy, Physics in Medicine and Biology 57 (2012) 591-608.

[29] C. K. Goh, K. C. Tan, Evolving the tradeoffs between Pareto-optimality and robustness in multi-objective evolutionary algorithms, Studies in Computational Intelligence 51 (2007) 457-478.

[30] D. Kuroiwa, G. M. Lee, On robust multiobjective optimization, Journal of Nonlinear and Convex Analysis 15 (2014) 1125-1136.

[31] L. Wang, Q. Li, R. Ding, M. Sun, G. Wang, Integrated scheduling of energy supply and demand in microgrids under uncertainty: A robust multi-objective optimization approach, Energy 130 (2017) 1-14.

[32] K. Deb, H. Gupta, Introducing robustness in multi-objective optimization, Evolutionary Computation 14 (2006) 463-494. 
[33] M. R. D. Quitoras, M. L. S. Abundo, L. A. M. Danao, A techno-economic assessment of wave energy resources in the Philippines, Renewable and Sustainable Energy Reviews 88 (2018) 68-81.

[34] Government of Northwest Territories, 2012 Northwest Territories Energy Charrette, Technical Report January, 2013.

[35] M. R. Quitoras, P. E. Campana, C. Crawford, Exploring electricity generation alternatives for Canadian Arctic communities using a multi-objective genetic algorithm approach, Energy Conversion and Management 210 (2020) 1-19.

[36] R. Dufo-Lopez, iHOGA User's manual, Technical Report February, 2020.

[37] G. Zubi, R. Dufo-lópez, G. Pasaoglu, N. Pardo, Techno-economic assessment of an off-grid PV system for developing regions to provide electricity for basic domestic needs : A 2020 2040 scenario, Applied Energy 176 (2016) 309-319.

[38] R. Dufo-lópez, E. Pérez-cebollada, J. L. Bernal-agustín, I. Martínez-ruiz, Optimisation of energy supply at off-grid healthcare facilities using Monte Carlo simulation, Energy Conversion and Management 113 (2016) 321-330.

[39] J. B. Fulzele, M. Daigavance, Sc cience Direct t Des ign and Optimiz zation of f Hybrid PV-Win nd Renew wable En nergy, Materials Today: Proceedings (2018).

[40] G. Zubi, G. Vincenzo, J. M. Lujano-rojas, K. El, D. Andrews, The unlocked potential of solar home systems ; an effective way to overcome domestic energy poverty in developing regions, Renewable Energy 132 (2019) 1425-1435.

[41] R. Dufo-López, J. L. Bernal-Agustín, J. M. Yusta-Loyo, J. A. Domínguez-Navarro, I. J. Ramírez-Rosado, J. Lujano, I. Aso, Multi-objective optimization minimizing cost and life cycle emissions of stand-alone PV-wind-diesel systems with batteries storage, Applied Energy 88 (2011) 4033-4041.

[42] R. Dufo-López, I. R. Cristóbal-Monreal, J. M. Yusta, Stochastic-heuristic methodology for the optimisation of components and control variables of PV-wind-diesel-battery stand-alone systems, Renewable Energy 99 (2016) 919-935.

[43] J.-p. Pinard, Wind Monitoring Update for Tuktoyaktuk, Technical Report 867, 2009.

[44] Government of Northwest Territories, CLIMATE OBSERVATIONS IN THE NORTHWEST TERRITORIES (1957-2012), Technical Report, 2012.

[45] F. R. Martins, S. A. Silva, E. B. Pereira, S. L. Abreu, The influence of cloud cover index on the accuracy of solar irradiance model estimates, Meteorology and Atmospheric Physics 99 (2008) 169-180.

[46] The Narwhal, How can Canada's North get off diesel?, 2019. URL: https://thenarwhal.ca/ how-canadas-north-get-off-diesel/.

[47] R. Billinton, W. Li, Reliability assessment of electric power systems using Monte Carlo methods, Springer Science+Business Media New York, 1994.

[48] I. Das, C. Canizares, Renewable Energy Deployment in Canadian Arctic - Phase I (PreFeasibility studies and community engagement report for Nunavut), Technical Report, World Wildlife Fund, Waterloo Institute for Sustainable Energy, 2016.

[49] HOMER Energy, HOMER Pro, 2019. URL: https://www.homerenergy .com/products/pro/ index.html.

[50] L. Tribioli, R. Cozzolino, L. Evangelisti, G. Bella, Energy management of an off-grid hybrid power plant with multiple energy storage systems, Energies 9 (2016).

[51] Trojan Battery Company, T-105 Deep-Cycle Flooded, 2020. URL: https://www. trojanbattery.com/product/t-105/. 
[52] Trojan Battery Company, TR 25.6-25 Li-ion Deep-Cycle Lithium, 2020. URL: https://www . trojanbattery.com/product/tr-25-6-25-li-ion/

[53] West Grid, What is Compute Canada, 2020. URL: https://www.westgrid.ca/ faq\{_\}prospective\{_\}users/what $\left\{_{-}\right\}$compute\{_\}canada.

[54] T. Tezer, R. Yaman, G. Yaman, Evaluation of approaches used for optimization of standalone hybrid renewable energy systems, Renewable and Sustainable Energy Reviews 73 (2017) 840-853.

[55] J. L. Sweeney, Modeling for Insights, not Numbers : the Experiences of the Energy Modeling Forum 1, OMEGA 10 (1982) 449-462.

[56] Hatch Ltd., Sachs Harbour Wind Scoping Study, Technical Report April, 2017.

[57] Qulliq Energy Corporation, Qulliq Energy Corporation Application for Commercial and Institutional Power Producers Pricing Structure, 2020. URL: https://www.qec.nu.ca/customer-care/generating-power/ commercial-and-institutional-power-producer-program.

[58] First Nations Power Authority, First Nations Power Authority: Bringing Experience and Expertise to First Nations, 2020. URL: https://fnpa.ca/home-3/.

[59] B. Morin, Can First Nations Power Authority transform the energy industry?, 2019. URL: https://www.nationalobserver.com/2019/11/24/news/ can-first-nations-power-authority-transform-energy-industry.

[60] National Energy Board, Energy Facts - Energy Use in Canada's North, Technical Report, 2011.

[61] T.-P. Frappé-Sénéclauze, D. Heerema, . Karen, T. Wu, Accelerating Market Transformation for High-Performance Building Enclosures (2016).

[62] J. J. Roberts, A. Marotta Cassula, J. L. Silveira, E. da Costa Bortoni, A. Z. Mendiburu, Robust multi-objective optimization of a renewable based hybrid power system, Applied Energy 223 (2018) 52-68. 